\title{
The Shrinking Projection Method for Solving Variational Inequality Problems and Fixed Point Problems in Banach Spaces
}

\author{
Rabian Wangkeeree and Rattanaporn Wangkeeree \\ Department of Mathematics, Faculty of Science, Naresuan University, Phitsanulok 65000, Thailand \\ Correspondence should be addressed to Rabian Wangkeeree, rabianw@nu.ac.th
}

Received 6 September 2009; Revised 17 October 2009; Accepted 19 October 2009

Recommended by Simeon Reich

\begin{abstract}
We consider a hybrid projection algorithm based on the shrinking projection method for two families of quasi- $\phi$-nonexpansive mappings. We establish strong convergence theorems for approximating the common element of the set of the common fixed points of such two families and the set of solutions of the variational inequality for an inverse-strongly monotone operator in the framework of Banach spaces. As applications, at the end of the paper we first apply our results to consider the problem of finding a zero point of an inverse-strongly monotone operator and we finally utilize our results to study the problem of finding a solution of the complementarity problem. Our results improve and extend the corresponding results announced by recent results.

Copyright (c) 2009 R. Wangkeeree and R. Wangkeeree. This is an open access article distributed under the Creative Commons Attribution License, which permits unrestricted use, distribution, and reproduction in any medium, provided the original work is properly cited.
\end{abstract}

\section{Introduction}

Let $E$ be a Banach space and let $C$ be a nonempty, closed, and convex subset of $E$. Let $A: C \rightarrow$ $E^{*}$ be an operator. The classical variational inequality problem [1] for $A$ is to find $x^{*} \in C$ such that

$$
\left\langle A x^{*}, y-x^{*}\right\rangle \geq 0, \quad \forall y \in C,
$$

where $E^{*}$ denotes the dual space of $E$ and $\langle\cdot, \cdot\rangle$ the generalized duality pairing between $E$ and $E^{*}$. The set of all solutions of $(1.1)$ is denoted by $\operatorname{VI}(A, C)$. Such a problem is connected with the convex minimization problem, the complementarity, the problem of finding a point $x^{*} \in E$ satisfying $0=A x^{*}$, and so on. First, we recall that a mapping $A: C \rightarrow E^{*}$ is said to be 
(i) monotone if $\langle A x-A y, x-y\rangle \geq 0$, for all $x, y \in C$,

(ii) $\alpha$-inverse-strongly monotone if there exists a positive real number $\alpha$ such that

$$
\langle A x-A y, x-y\rangle \geq \alpha\|A x-A y\|^{2}, \quad \forall x, y \in C .
$$

In this paper, we assume that the operator $A$ satisfies the following conditions:

(C1) $A$ is $\alpha$-inverse-strongly monotone,

(C2) $\|A y\| \leq\|A y-A u\|$ for all $y \in C$ and $u \in V I(A, C)$.

Let $J$ be the normalized duality mapping from $E$ into $2^{E^{*}}$ given by

$$
J x=\left\{x^{*} \in E^{*}:\left\langle x, x^{*}\right\rangle=\|x\|\left\|x^{*}\right\|,\|x\|=\left\|x^{*}\right\|\right\}, \quad \forall x \in E .
$$

It is well known that if $E^{*}$ is uniformly convex, then $J$ is uniformly continuous on bounded subsets of $E$. Some properties of the duality mapping are given in [2-4].

Recall that a mapping $T: C \rightarrow C$ is said to be nonexpansive if

$$
\|T x-T y\| \leq\|x-y\|, \quad \forall x, y \in C .
$$

If $C$ is a nonempty closed convex subset of a Hilbert space $H$ and $P_{C}: H \rightarrow C$ is the metric projection of $H$ onto $C$, then $P_{C}$ is a nonexpansive mapping. This fact actually characterizes Hilbert spaces and, consequently, it is not available in more general Banach spaces. In this connection, Alber [5] recently introduced a generalized projection operator $C$ in a Banach space $E$ which is an analogue of the metric projection in Hilbert spaces.

Consider the functional $\phi: E \times E \rightarrow \mathbb{R}$ defined by

$$
\phi(y, x)=\|y\|^{2}-2\langle y, J x\rangle+\|x\|^{2}
$$

for all $x, y \in E$, where $J$ is the normalized duality mapping from $E$ to $E^{*}$. Observe that, in a Hilbert space $H,(1.5)$ reduces to $\phi(y, x)=\|x-y\|^{2}$ for all $x, y \in H$. The generalized projection $\Pi_{C}: E \rightarrow C$ is a mapping that assigns to an arbitrary point $x \in E$ the minimum point of the functional $\phi(y, x)$, that is, $\Pi_{C} x=x^{*}$, where $x^{*}$ is the solution to the minimization problem:

$$
\phi\left(x^{*}, x\right)=\inf _{y \in C} \phi(y, x)
$$

The existence and uniqueness of the operator $\Pi_{C}$ follows from the properties of the functional $\phi(y, x)$ and strict monotonicity of the mapping $J$ (see, e.g., $[2,5-7]$ ). In Hilbert spaces, $\Pi_{C}=$ $P_{C}$, where $P_{C}$ is the metric projection. It is obvious from the definition of the function $\phi$ that

(1) $(\|y\|-\|x\|)^{2} \leqslant \phi(y, x) \leqslant(\|y\|+\|x\|)^{2}$ for all $x, y \in E$,

(2) $\phi(x, y)=\phi(x, z)+\phi(z, y)+2\langle x-z, J z-J y\rangle$ for all $x, y, z \in E$,

(3) $\phi(x, y)=\langle x, J x-J y\rangle+\langle y-x, J y\rangle \leqslant\|x\|\|J x-J y\|+\|y-x\|\|y\|$ for all $x, y \in E$, 
(4) if $E$ is a reflexive, strictly convex, and smooth Banach space, then for all $x, y \in E$,

$$
\phi(x, y)=0 \quad \text { iff } x=y .
$$

For more details see $[2,3]$. Let $C$ be a closed convex subset of $E$, and let $T$ be a mapping from $C$ into itself. We denote by $F(T)$ the set of fixed point of $T$. A point $p$ in $C$ is said to be an asymptotic fixed point of $T$ [8] if $C$ contains a sequence $\left\{x_{n}\right\}$ which converges weakly to $p$ such that $\lim _{n \rightarrow \infty}\left\|x_{n}-T x_{n}\right\|=0$. The set of asymptotic fixed points of $T$ will be denoted by $\widehat{F}(T)$. A mapping $T$ from $C$ into itself is called nonexpansive if $\|T x-T y\| \leqslant\|x-y\|$ for all $x, y \in C$ and relatively nonexpansive [9-11] if $\widehat{F}(T)=F(T)$ and $\phi(p, T x) \leqslant \phi(p, x)$ for all $x \in C$ and $p \in F(T)$. The asymptotic behavior of relatively nonexpansive mappings which was studied in [9-11] is of special interest in the convergence analysis of feasibility, optimization, and equilibrium methods for solving the problems of image processing, rational resource allocation, and optimal control. The most typical examples in this regard are the Bregman projections and the Yosida type operators which are the cornerstones of the common fixed point and optimization algorithms discussed in [12] (see also the references therein).

The mapping $T$ is said to be $\phi$-nonexpansive if $\phi(T x, T y) \leq \phi(x, y)$ for all $x, y \in C$. $T$ is said to be quasi- $\phi$-nonexpansive if $F(T) \neq \emptyset$ and $\phi(p, T x) \leq \phi(p, x)$ for all $x \in C$ and $p \in F(T)$.

Remark 1.1. The class of quasi- $\phi$-nonexpansive is more general than the class of relatively nonexpansive mappings $[9,10,13-15]$ which requires the strong restriction $\widehat{F}(T)=F(T)$.

Next, we give some examples which are closed quasi- $\phi$-nonexpansive [16].

Example 1.2. (1) Let $E$ be a uniformly smooth and strictly convex Banach space and let $A$ be a maximal monotone mapping from $E$ to $E$ such that its zero set $A^{-1} 0$ is nonempty. The resolvent $J_{r}=(J+r A)^{-1} J$ is a closed quasi- $\phi$-nonexpansive mapping from $E$ onto $D(A)$ and $F\left(J_{r}\right)=A^{-1} 0$.

(2) Let $\Pi_{C}$ be the generalized projection from a smooth, strictly convex, and reflexive Banach space $E$ onto a nonempty closed convex subset $C$ of $E$. Then $\Pi_{C}$ is a closed and quasi$\phi$-nonexpansive mapping from $E$ onto $C$ with $F\left(\Pi_{C}\right)=C$.

Iiduka and Takahashi [17] introduced the following algorithm for finding a solution of the variational inequality for an operator $A$ that satisfies conditions (C1)-(C2) in a 2 uniformly convex and uniformly smooth Banach space $E$. For an initial point $x_{0}=x \in C$, define a sequence $\left\{x_{n}\right\}$ by

$$
x_{n+1}=\Pi_{C} J^{-1}\left(J x_{n}-\lambda_{n} x_{n}\right), \quad \forall n \geq 0 .
$$

where $J$ is the duality mapping on $E$, and $\Pi_{C}$ is the generalized projection of $E$ onto $C$. Assume that $\lambda_{n} \in[a, b]$ for some $a, b$ with $0<a<b<c^{2} \alpha / 2$ where $1 / c$ is the 2 uniformly convexity constant of $E$. They proved that if $J$ is weakly sequentially continuous, then the sequence $\left\{x_{n}\right\}$ converges weakly to some element $z$ in $\operatorname{VI}(A, C)$ where $z=$ $\lim _{n \rightarrow \infty} \Pi_{V I(A, C)}\left(x_{n}\right)$. 
The problem of finding a common element of the set of the variational inequalities for monotone mappings in the framework of Hilbert spaces and Banach spaces has been intensively studied by many authors; see, for instance, [18-20] and the references cited therein.

On the other hand, one classical way to study nonexpansive mappings is to use contractions to approximate a nonexpansive mapping (see [21]). More precisely, let $t \in(0,1)$ and define a contraction $G_{t}: C \rightarrow C$ by $G_{t} x=t x_{0}+(1-t) T x$ for all $x \in C$, where $x_{0} \in C$ is a fixed point in $C$. Applying Banach's Contraction Principle, there exists a unique fixed point $x_{t}$ of $G_{t}$ in $C$. It is unclear, in general, what is the behavior of $x_{t}$ as $t \rightarrow 0$ even if $T$ has a fixed point. However, in the case of $T$ having a fixed point, Browder [21] proved that the net $\left\{x_{t}\right\}$ defined by $x_{t}=t x_{0}+(1-t) T x_{t}$ for all $t \in(0,1)$ converges strongly to an element of $F(T)$ which is nearest to $x_{0}$ in a real Hilbert space. Motivated by Browder [21], Halpern [22] proposed the following iteration process:

$$
x_{0} \in C, \quad x_{n+1}=\alpha_{n} x_{0}+\left(1-\alpha_{n}\right) T x_{n}, \quad n \geqslant 0
$$

and proved the following theorem.

Theorem H. Let $C$ be a bounded closed convex subset of a Hilbert space $H$ and let $T$ be a nonexpansive mapping on $C$. Define a real sequence $\left\{\alpha_{n}\right\}$ in $[0,1]$ by $\alpha_{n}=n^{-\theta}, 0<\theta<1$. Define a sequence $\left\{x_{n}\right\}$ by (1.9). Then $\left\{x_{n}\right\}$ converges strongly to the element of $F(T)$ which is the nearest to $u$.

Recently, Martinez-Yanes and Xu [23] have adapted Nakajo and Takahashi's [24] idea to modify the process (1.9) for a single nonexpansive mapping $T$ in a Hilbert space $H$ :

$$
\begin{gathered}
x_{0}=x \in C \text { chosen arbitrary, } \\
y_{n}=\alpha_{n} x_{0}+\left(1-\alpha_{n}\right) T x_{n}, \\
C_{n}=\left\{v \in C:\left\|y_{n}-v\right\|^{2} \leqslant\left\|x_{n}-v\right\|^{2}+\alpha_{n}\left(\left\|x_{0}\right\|^{2}+2\left\langle x_{n}-x_{0}, v\right\rangle\right)\right\}, \\
Q_{n}=\left\{v \in C:\left\langle x_{n}-v, x_{0}-x_{n}\right\rangle \geqslant 0\right\}, \\
x_{n+1}=P_{C_{n} \cap Q_{n}} x_{0},
\end{gathered}
$$

where $P_{C}$ denotes the metric projection of $H$ onto a closed convex subset $C$ of $H$. They proved that if $\left\{\alpha_{n}\right\} \subset(0,1)$ and $\lim _{n \rightarrow \infty} \alpha_{n}=0$, then the sequence $\left\{x_{n}\right\}$ generated by (1.10) converges strongly to $P_{F(T)} x$.

In [15] (see also [13]), Qin and Su improved the result of Martinez-Yanes and Xu [23] from Hilbert spaces to Banach spaces. To be more precise, they proved the following theorem.

Theorem QS. Let $E$ be a uniformly convex and uniformly smooth Banach space, let $C$ be a nonempty closed convex subset of $E$, and let $T: C \rightarrow C$ be a relatively nonexpansive mapping. Assume that 
$\left\{\alpha_{n}\right\}$ is a sequence in $(0,1)$ such that $\lim _{n \rightarrow \infty} \alpha_{n}=0$. Define a sequence $\left\{x_{n}\right\}$ in $C$ by the following algorithm:

$$
\begin{gathered}
x_{0}=x \in C \text { chosen arbitrary, } \\
y_{n}=J^{-1}\left(\alpha_{n} J x_{0}+\left(1-\alpha_{n}\right) J T x_{n}\right), \\
C_{n}=\left\{v \in C: \phi\left(v, y_{n}\right) \leq \alpha_{n} \phi\left(v, y_{n}\right)+\left(1-\alpha_{n}\right) \phi\left(v, x_{n}\right)\right\}, \\
Q_{n}=\left\{v \in C:\left\langle x_{n}-v, J x_{0}-J x_{n}\right\rangle \geqslant 0\right\}, \\
x_{n+1}=\Pi_{C_{n} \cap Q_{n}} x_{0},
\end{gathered}
$$

where $J$ is the single-valued duality mapping on E. If $F(T)$ is nonempty, then $\left\{x_{n}\right\}$ converges to $\Pi_{F(T)} x_{0}$.

In [14], Plubtieng and Ungchittrakool introduced the following hybrid projection algorithm for a pair of relatively nonexpansive mappings:

$$
\begin{gathered}
x_{0}=x \in C \text { chosen arbitrary, } \\
z_{n}=J^{-1}\left(\beta_{n}^{(1)} J x_{n}+\beta_{n}^{(2)} J T x_{n}+\beta_{n}^{(3)} J S x_{n}\right), \\
y_{n}=J^{-1}\left(\alpha_{n} J x_{0}+\left(1-\alpha_{n}\right) J z_{n}\right), \\
H_{n}=\left\{z \in C: \phi\left(z, y_{n}\right) \leqslant \phi\left(z, x_{n}\right)+\alpha_{n}\left(\left\|x_{0}\right\|^{2}+2\left\langle z, J x_{n}-J x\right\rangle\right)\right\}, \\
W_{n}=\left\{z \in C:\left\langle x_{n}-z, J x-J x_{n}\right\rangle \geqslant 0\right\}, \\
x_{n+1}=P_{H_{n} \cap W_{n}} x, \quad n=0,1,2, \ldots,
\end{gathered}
$$

where $\left\{\alpha_{n}\right\},\left\{\beta_{n}^{(1)}\right\},\left\{\beta_{n}^{(2)}\right\}$, and $\left\{\beta_{n}^{(3)}\right\}$ are sequences in $[0,1]$ satisfying $\beta_{n}^{(1)}+\beta_{n}^{(2)}+\beta_{n}^{(3)}=1$ for all $n \in \mathbb{N} \cup\{0\}$ and $T, S$ are relatively nonexpansive mappings and $J$ is the single-valued duality mapping on $E$. They proved, under appropriate conditions on the parameters, that the sequence $\left\{x_{n}\right\}$ generated by (1.12) converges strongly to a common fixed point of $T$ and $S$.

Very recently, Qin et al. [25] introduced a new hybrid projection algorithm for two families of quasi- $\phi$-nonexpansive mappings which are more general than relatively nonexpansive mappings to have strong convergence theorems in the framework of Banach spaces. To be more precise, they proved the following theorem.

Theorem QCKZ. Let $E$ be a uniformly convex and uniformly smooth Banach space, and let $C$ be a nonempty closed convex subset of $E$. Let $\left\{S_{i}\right\}_{i \in I}$ and $\left\{T_{i}\right\}_{i \in I}$ be two families of closed quasi- $\phi$ nonexpansive mappings of $C$ into itself with $F:=\bigcap_{i \in I} F\left(T_{i}\right) \cap \bigcap_{i \in I} F\left(S_{i}\right)$ being nonempty, where 
I is an index set. Let the sequence $\left\{x_{n}\right\}$ be generated by the following manner:

$$
\begin{gathered}
x_{0}=x \in C \text { chosen arbitrary, } \\
z_{n, i}=J^{-1}\left(\beta_{n, i}^{(1)} J x_{n}+\beta_{n, i}^{(2)} J T_{i} x_{n}+\beta_{n, i}^{(3)} J S_{i} x_{n}\right), \\
y_{n, i}=J^{-1}\left(\alpha_{n, i} J x_{0}+\left(1-\alpha_{n, i}\right) J z_{n, i}\right), \\
C_{n, i}=\left\{u \in C: \phi\left(u, y_{n, i}\right) \leqslant \phi\left(u, x_{n}\right)+\alpha_{n, i}\left(\left\|x_{0}\right\|^{2}+2\left\langle u, J x_{n}-J x_{n}\right\rangle\right)\right\}, \\
C_{n}=\bigcap_{i \in I} C_{n, i}, \\
Q_{0}=C, \\
Q_{n}=\left\{u \in Q_{n-1}:\left\langle x_{n}-u, J x_{0}-J x_{n}\right\rangle \geq 0\right\}, \\
x_{n+1}=\prod_{C_{n} \cap Q_{n}} x_{0}, \quad n=0,1,2, \ldots,
\end{gathered}
$$

where $J$ is the duality mapping on $E$, and $\left\{\alpha_{n, i}\right\}$ and $\left\{\beta_{n, i}^{(i)}\right\}(i=1,2,3, \ldots)$ are sequences in $(0,1)$ satisfying

(i) $\beta_{n, i}^{(1)}+\beta_{n, i}^{(2)}+\beta_{n, i}^{(3)}=1$ for all $i \in I$,

(ii) $\lim _{n \rightarrow \infty} \alpha_{n, i}=0$ for all $i \in I$,

(iii) $\liminf _{n \rightarrow \infty} \beta_{n, i}^{(2)} \beta_{n, i}^{(3)}>0$ and $\lim _{n \rightarrow \infty} \beta_{n, i}^{(1)}=0$ for all $i \in I$.

Then the sequence $\left\{x_{n}\right\}$ converges strongly to $\Pi_{F} x_{0}$.

On the other hand, recently, Takahashi et al. [26] introduced the following hybrid method (1.14) which is different from Nakajo and Takahashi's [24] hybrid method. It is called the shrinking projection method. They obtained the following result.

Theorem NT. Let $C$ be a nonempty closed convex subset of a Hilbert space $H$. Let $T$ be a nonexpansive mapping of $C$ into $H$ such that $F(T) \neq \emptyset$ and let $x_{0} \in H$. For $C_{1}=C$ and $x_{1}=P_{C_{1}} x_{0}$, define a sequence $\left\{x_{n}\right\}$ of $C$ as follows:

$$
\begin{gathered}
y_{n}=\alpha_{n} x_{n}+\left(1-\alpha_{n}\right) T x_{n}, \\
C_{n+1}=\left\{z \in C_{n}:\left\|y_{n}-z\right\| \leq\left\|x_{n}-z\right\|\right\}, \\
x_{n+1}=P_{C_{n+1}} x_{0}, \quad \forall n \geq 0,
\end{gathered}
$$

where $0 \leq \alpha_{n}<a<1$ for all $n \in \mathbb{N}$. Then $\left\{x_{n}\right\}$ converges strongly to $z_{0}=P_{F(T)}\left(x_{0}\right)$.

Motivated and inspired by Iiduka and Takahashi [17], Martinez-Yanes and Xu [23], Matsushita and Takahashi [13], Plubtieng and Ungchittrakool [14], Qin and Su [15], Qin et al. [25], and Takahashi et al. [26], we introduce a new hybrid projection algorithm basing on the shrinking projection method for two families of quasi- $\phi$-nonexpansive mappings which are more general than relatively nonexpansive mappings to have strong convergence theorems 
for approximating the common element of the set of common fixed points of two families of quasi- $\phi$-nonexpansive mappings and the set of solutions of the variational inequality for an inverse-strongly monotone operator in the framework of Banach spaces. As applications, the problem of finding a zero point of an inverse-strongly monotone operator and the problem of finding a solution of the complementarity problem are studied. Our results improve and extend the corresponding results announced by recent results.

\section{Preliminaries}

Let $E$ be a real Banach space with duality mapping $J$. We denote strong convergence of $\left\{x_{n}\right\}$ to $x$ by $x_{n} \rightarrow x$ and weak convergence by $x_{n} \rightarrow x$. A multivalued operator $T: E \rightarrow 2^{E^{*}}$ with domain $D(T)$ and range $R(T)$ is said to be monotone if $\left\langle x_{1}-x_{2}, y_{1}-y_{2}\right\rangle \geq 0$ for each $x_{i} \in D(T)$ and $y_{i} \in T x_{i}, i=1,2$. A monotone operator $T$ is said to be maximal if its graph $G(T)=\{(x, y): y \in T x\}$ is not properly contained in the graph of any other monotone operators.

A Banach space $E$ is said to be strictly convex if $\|(x+y) / 2\|<1$ for all $x, y \in E$ with $\|x\|=\|y\|=1$ and $x \neq y$. It is said to be uniformly convex if $\lim _{n \rightarrow \infty}\left\|x_{n}-y_{n}\right\|=0$ for any two sequences $\left\{x_{n}\right\},\left\{y_{n}\right\}$ in $E$ such that $\left\|x_{n}\right\|=\left\|y_{n}\right\|=1$ and $\lim _{n \rightarrow \infty}\left\|\left(x_{n}+y_{n}\right) / 2\right\|=1$. Let $U=\{x \in E:\|x\|=1\}$ be the unit sphere of $E$. Then the Banach space $E$ is said to be smooth provided that

$$
\lim _{t \rightarrow 0} \frac{\|x+t y\|-\|x\|}{t}
$$

exists for each $x, y \in U$. It is also said to be uniformly smooth if the limit is attained uniformly for $x, y \in U$. It is well know that if $E$ is smooth, then the duality mapping $J$ is single valued. It is also known that if $E$ is uniformly smooth, then $J$ is uniformly norm-to-norm continuous on bounded subset of $E$. Some properties of the duality mapping are given in [2, 3, 27-29]. We define the function $\delta:[0,2] \rightarrow[0,1]$ which is called the modulus of convexity of $E$ as follows:

$$
\delta(\varepsilon)=\inf \left\{1-\left\|\frac{x+y}{2}\right\|: x, y \in C,\|x\|=\|y\|=1,\|x-y\| \geq \varepsilon\right\}
$$

Then $E$ is said to be 2 uniformly convex if there exists a constant $c>0$ such that constant $\delta(\varepsilon)>c \varepsilon^{2}$ for all $\varepsilon \in(0,2]$. Constant $1 / c$ is called the 2 uniformly convexity constant of $E$. A 2 uniformly convex Banach space is uniformly convex; see [30,31] for more details. We know the following lemma of 2 uniformly convex Banach spaces.

Lemma 2.1 (see $[32,33])$. Let $E$ be a 2 uniformly convex Banach, then for all $x, y$ from any bounded set of $E$ and $j x \in J x, j y \in J y$,

$$
\langle x-y, j x-j y\rangle \geq \frac{c^{2}}{2}\|x-y\|^{2}
$$

where $1 / c$ is the 2 uniformly convexity constant of $E$. 
Now we present some definitions and lemmas which will be applied in the proof of the main result in the next section.

Lemma 2.2 (Kamimura and Takahashi [7]). Let E be a uniformly convex and smooth Banach space and let $\left\{y_{n}\right\},\left\{z_{n}\right\}$ be two sequences of $E$ such that either $\left\{y_{n}\right\}$ or $\left\{z_{n}\right\}$ is bounded. If $\lim _{n \rightarrow \infty} \phi\left(y_{n}, z_{n}\right)=0$, then $\lim _{n \rightarrow \infty}\left\|y_{n}-z_{n}\right\|=0$.

Lemma 2.3 (Alber [5]). Let $C$ be a nonempty closed convex subset of a smooth Banach space $E$ and $x \in E$. Then, $x_{0}=\Pi_{C} x$ if and only if $\left\langle x_{0}-y, J x-J x_{0}\right\rangle \geqslant 0$ for any $y \in C$.

Lemma 2.4 (Alber [5]). Let E be a reflexive, strictly convex, and smooth Banach space, let $C$ be a nonempty closed convex subset of $E$, and let $x \in E$. Then

$$
\phi\left(y, \Pi_{C} x\right)+\phi\left(\Pi_{C} x, x\right) \leqslant \phi(y, x)
$$

for all $y \in C$.

Lemma 2.5 (Qin et al. [25]). Let E be a uniformly convex and smooth Banach space, let $C$ be a closed convex subset of $E$, and let $T$ be a closed quasi- $\phi$-nonexpansive mapping of $C$ into itself. Then $F(T)$ is a closed convex subset of $C$.

Let $E$ be a reflexive strictly convex, smooth, and uniformly Banach space and the duality mapping from $E$ to $E^{*}$. Then $J^{-1}$ is also single valued, one to one, and surjective, and it is the duality mapping from $E^{*}$ to $E$. We need the following mapping $V$ which is studied in Alber [5]:

$$
V\left(x, x^{*}\right)=\|x\|^{2}-2\left\langle x, x^{*}\right\rangle+\|x\|^{2}
$$

for all $x \in E$ and $x^{*} \in E^{*}$. Obviously, $V\left(x, x^{*}\right)=\phi\left(x, J^{-1}\left(x^{*}\right)\right)$. We know the following lemma.

Lemma 2.6 (Kamimura and Takahashi [7]). Let E be a reflexive, strictly convex, and smooth Banach space, and let $V$ be as in (2.5). Then

$$
V\left(x, x^{*}\right)+2\left\langle J^{-1}\left(x^{*}\right)-x, y^{*}\right\rangle \leq V\left(x, x^{*}+y^{*}\right)
$$

for all $x \in E$ and $x^{*}, y^{*} \in E^{*}$.

Lemma 2.7 (see [34, Lemma 1.4]). Let $E$ be a uniformly convex Banach space and $B_{r}(0)=\{x \in$ $E:\|x\| \leqslant r\}$ be a closed ball of $E$. Then there exists a continuous strictly increasing convex function $g:[0, \infty) \rightarrow[0, \infty)$ with $g(0)=0$ such that

$$
\|\lambda x+\mu y+\gamma z\|^{2} \leqslant \lambda\|x\|^{2}+\mu\|y\|^{2}+\gamma\|z\|^{2}-\lambda \mu g(\|x-y\|)
$$

for all $x, y, z \in B_{r}(0)$ and $\lambda, \mu, \gamma \in[0,1]$ with $\lambda+\mu+\gamma=1$. 
An operator $A$ of $C$ into $E^{*}$ is said to be hemicontinuous if, for all $x, y \in C$, the mapping $F$ of $[0,1)$ into $E^{*}$ defined by $F(t)=A(t x+(1-t) y)$ is continuous with respect to the weak* topology of $E^{*}$. We denote by $N_{C}(v)$ the normal cone for $C$ at a point $v \in C$, that is,

$$
N_{C}(v)=\left\{x^{*} \in E^{*}:\left\langle v-y, x^{*}\right\rangle \geq 0, \forall y \in C\right\} .
$$

Lemma 2.8 (see [35]). Let $C$ be a nonempty closed convex subset of a Banach space $E$ and $A$ a monotone, hemicontinuous operator of $C$ into $E^{*}$. Let $T \subset E \times E^{*}$ be an operator defined as follows:

$$
T v= \begin{cases}A v+N_{C}(v), & v \in C, \\ \emptyset, & v \notin C .\end{cases}
$$

Then $T$ is maximal monotone and $T^{-1} 0=\operatorname{VI}(A, C)$.

\section{Main Results}

In this section, we prove strong convergence theorem which is our main result.

Theorem 3.1. Let $E$ be a 2 uniformly convex and uniformly smooth Banach space, and let $C$ be a nonempty closed convex subset of E. Let $A$ be an operator of $C$ into $E^{*}$ satisfying (C1) and (C2), and let $\left\{S_{i}\right\}_{i \in I}$ and $\left\{T_{i}\right\}_{i \in I}$ be two families of closed quasi- $\phi$-nonexpansive mappings of $C$ into itself with $F:=\bigcap_{i \in I} F\left(T_{i}\right) \cap \bigcap_{i \in I} F\left(S_{i}\right) \cap V I(A, C)$ being nonempty, where $I$ is an index set. Let $\left\{x_{n}\right\}$ be a sequence generated by the following manner:

$$
\begin{gathered}
x_{0} \in C \text { chosen arbitrary, } \\
C_{1, i}=C, \quad C_{1}=\bigcap_{i=1}^{\infty} C_{1, i} \quad x_{1}=\Pi_{C_{1}}\left(x_{0}\right) \quad \forall i \in I, \\
w_{n, i}=\prod_{C} J^{-1}\left(J x_{n}-\lambda_{n, i} A x_{n}\right), \\
z_{n, i}=J^{-1}\left(\beta_{n, i}^{(1)} J x_{n}+\beta_{n, i}^{(2)} J T_{i} x_{n}+\beta_{n, i}^{(3)} J S_{i} w_{n, i}\right), \\
y_{n, i}=J^{-1}\left(\alpha_{n, i} J x_{0}+\left(1-\alpha_{n, i}\right) J z_{n, i}\right), \\
C_{n+1, i}=\left\{u \in C_{n, i}: \phi\left(u, y_{n, i}\right) \leqslant \phi\left(u, x_{n}\right)+\alpha_{n, i}\left(\left\|x_{0}\right\|^{2}+2\left\langle u, J x_{n}-J x_{0}\right\rangle\right)\right\}, \\
C_{n+1}=\bigcap_{i \in I} C_{n+1, i}, \\
x_{n+1}=\prod_{C_{n+1}} x_{0}, \quad \forall n \geq 0,
\end{gathered}
$$

where $J$ is the duality mapping on $E$, and $\left\{\lambda_{n, i}\right\},\left\{\alpha_{n, i}\right\}$, and $\left\{\beta_{n, i}^{(j)}\right\} \quad(j=1,2,3)$ are sequences in $(0,1)$ satisfying the following conditions:

(i) $\lim _{n \rightarrow \infty} \alpha_{n, i}=0$ for all $i \in I$;

(ii) for all $i \in I,\left\{\lambda_{n, i}\right\} \subset[a, b]$ for some $a, b$ with $0<a<b<c^{2} \alpha / 2$, where $1 / c$ is the 2 uniformly convexity constant of $E$; 
(iii) $\beta_{n, i}^{(1)}+\beta_{n, i}^{(2)}+\beta_{n, i}^{(3)}=1$ for all $i \in I$ and if one of the following conditions is satisfied:

(a) $\liminf _{n \rightarrow \infty} \beta_{n, i}^{(1)} \beta_{n, i}^{(l)}>0$ for all $l=2,3$ and for all $i \in I$,

(b) $\liminf _{n \rightarrow \infty} \beta_{n, i}^{(2)} \beta_{n, i}^{(3)}>0$ and $\lim _{n \rightarrow \infty} \beta_{n, i}^{(1)}=0$ for all $i \in I$.

Then the sequence $\left\{x_{n}\right\}$ converges strongly to $\Pi_{F} x_{0}$, where $\Pi_{F}$ is the generalized projection from $C$ onto $F$.

Proof. We divide the proof into six steps.

Step 1. Show that $\Pi_{F} x_{0}$ and $\Pi_{C_{n+1}} x_{0}$ are well defined.

To this end, we prove first that $F$ is closed and convex. It is obvious that $V I(A, C)$ is a closed convex subset of $C$. By Lemma 2.5, we know that $\bigcap_{i \in I} F\left(T_{i}\right) \cap \bigcap_{i \in I} F\left(S_{i}\right)$ is closed and convex. Hence $F:=\bigcap_{i \in I} F\left(T_{i}\right) \cap \bigcap_{i \in I} F\left(S_{i}\right) \cap V I(A, C)$ is a nonempty, closed, and convex subset of $C$. Consequently, $\Pi_{F} x_{0}$ is well defined.

We next show that $C_{n+1}$ is convex for each $n \geq 0$. From the definition of $C_{n}$, it is obvious that $C_{n}$ is closed for each $n \geq 0$. Notice that

$$
C_{n+1, i}=\left\{u \in C_{n, i}: \phi\left(u, y_{n, i}\right) \leq \phi\left(u, x_{n}\right)+\alpha_{n, i}\left(\left\|x_{0}\right\|^{2}+2\left\langle u, J x_{n}-J x_{0}\right\rangle\right)\right\}
$$

is equivalent to

$$
C_{n+1, i}^{\prime}=\left\{u \in C_{n, i}: 2\left\langle u, J x_{n}-J y_{n, i}\right\rangle-2 \alpha_{n, i}\left\langle u, J x_{n}-J x_{0}\right\rangle \leq\left\|x_{n}\right\|^{2}-\left\|y_{n, i}\right\|^{2}+\alpha_{n, i}\left\|x_{0}\right\|^{2}\right\} .
$$

It is easy to see that $C_{n+1, i}^{\prime}$ is closed and convex for all $n \geq 0$ and $i \in I$. Therefore, $C_{n+1}=$ $\bigcap_{i \in I} C_{n+1, i}=\bigcap_{i \in I} C_{n+1, i}^{\prime}$ is closed and convex for every $n \geq 0$. This shows that $\Pi_{C_{n+1}} x_{0}$ is well defined.

Step 2. Show that $F:=\bigcap_{i \in I} F\left(T_{i}\right) \cap \bigcap_{i \in I} F\left(S_{i}\right) \cap V I(A, C) \subset C_{n}$ for all $n \geq 0$.

Put $v_{n, i}=J^{-1}\left(J x_{n}-\lambda_{n, i} A x_{n}\right)$. We have to show that $F \subset C_{n}$ for all $n \geq 0$. For all $u \in F$, we know from Lemmas 2.4 and 2.6 that

$$
\begin{aligned}
\phi\left(u, w_{n, i}\right) & =\phi\left(u, \Pi_{C} v_{n, i}\right) \\
& \leq \phi\left(u, v_{n, i}\right) \\
& =\phi\left(u, J^{-1}\left(J x_{n}-\lambda_{n, i} A x_{n}\right)\right) \\
& =V\left(u, J x_{n}-\lambda_{n, i} A x_{n}\right) \\
& \leq V\left(u,\left(J x_{n}-\lambda_{n, i} A x_{n}\right)+\lambda_{n, i} A x_{n}\right)-2\left\langle J^{-1}\left(J x_{n}-\lambda_{n, i} A x_{n}\right)-u, \lambda_{n, i} A x_{n}\right\rangle \\
& =V\left(u, J x_{n}\right)-2 \lambda_{n, i}\left\langle v_{n, i}-u, A x_{n}\right\rangle \\
& =\phi\left(u, x_{n}\right)-2 \lambda_{n, i}\left\langle x_{n}-u, A x_{n}\right\rangle+2\left\langle v_{n, i}-x_{n}-\lambda_{n, i} A x_{n}\right\rangle .
\end{aligned}
$$


Abstract and Applied Analysis

Since $u \in V I(A, C)$ and from condition (C1), we have

$$
\begin{aligned}
-2 \lambda_{n, i}\left\langle x_{n}-u, A x_{n}\right\rangle & =-2 \lambda_{n, i}\left\langle x_{n}-u, A x_{n}-A u\right\rangle-2 \lambda_{n, i}\left\langle x_{n}-u, A u\right\rangle \\
& \leq-2 \alpha \lambda_{n, i}\left\|A x_{n}-A u\right\|^{2} .
\end{aligned}
$$

From Lemma 2.1, and condition (C2), we also have

$$
\begin{aligned}
2\left\langle v_{n, i}-x_{n},-\lambda_{n, i} A x_{n}\right\rangle & =2\left\langle J^{-1}\left(J x_{n}-\lambda_{n, i} A x_{n}\right)-J^{-1}\left(J x_{n}\right),-\lambda_{n, i} A x_{n}\right\rangle \\
& \leq 2\left\|J^{-1}\left(J x_{n}-\lambda_{n, i} A x_{n}\right)-J^{-1}\left(J x_{n}\right)\right\|\left\|\lambda_{n, i} A x_{n}\right\| \\
& \leq \frac{4}{c^{2}}\left\|J J^{-1}\left(J x_{n}-\lambda_{n, i} A x_{n}\right)-J J^{-1}\left(J x_{n}\right)\right\|\left\|\lambda_{n, i} A x_{n}\right\| \\
& =\frac{4}{c^{2}}\left\|\left(J x_{n}-\lambda_{n, i} A x_{n}\right)-\left(J x_{n}\right)\right\|\left\|\lambda_{n, i} A x_{n}\right\| \\
& \leq \frac{4}{c^{2}} \lambda_{n, i}^{2}\left\|A x_{n}\right\|^{2} \\
& \leq \frac{4}{c^{2}} \lambda_{n, i}^{2}\left\|A x_{n}-A u\right\|^{2} .
\end{aligned}
$$

Subtituting (3.6) and (3.5) into (3.4) and using the assumption (ii), we obtain

$$
\begin{aligned}
\phi\left(u, w_{n, i}\right) & \leq \phi\left(u, x_{n}\right)-2 \alpha \lambda_{n, i}\left\|A x_{n}-A u\right\|^{2}+\frac{4}{c^{2}} \lambda_{n, i}^{2}\left\|A x_{n}-A u\right\|^{2} . \\
& \leq \phi\left(u, x_{n}\right)+2 \lambda_{n, i}\left(\frac{2}{c^{2}} \lambda_{n, i}-\alpha\right)\left\|A x_{n}-A u\right\|^{2} \\
& \leq \phi\left(u, x_{n}\right) .
\end{aligned}
$$

It follows from the convexity of $\|\cdot\|^{2}$ and (3.7) that

$$
\begin{aligned}
\phi\left(u, z_{n, i}\right)= & \phi\left(u, J^{-1}\left(\beta_{n, i}^{(1)} J x_{n}+\beta_{n, i}^{(2)} J T_{i} x_{n}+\beta_{n, i}^{(3)} J S_{i} w_{n, i}\right)\right) \\
= & \|u\|^{2}-2\left\langle u, \beta_{n, i}^{(1)} J x_{n}+\beta_{n, i}^{(2)} J T_{i} x_{n}+\beta_{n, i}^{(3)} J S_{i} w_{n, i}\right\rangle \\
& +\left\|\beta_{n, i}^{(1)} J x_{n}+\beta_{n, i}^{(2)} J T_{i} x_{n}+\beta_{n, i}^{(3)} J S_{i} w_{n, i}\right\|^{2} \\
\leq & \|u\|^{2}-2 \beta_{n, i}^{(1)}\left\langle u, J x_{n}\right\rangle-2 \beta_{n, i}^{(2)}\left\langle u, J T_{i} x_{n}\right\rangle-2 \beta_{n, i}^{(2)}\left\langle u, J S_{i} w_{n, i}\right\rangle \\
& +\beta_{n, i}^{(1)}\left\|J x_{n}\right\|^{2}+\beta_{n, i}^{(2)}\left\|J T_{i} x_{n}\right\|^{2}+\beta_{n, i}^{(3)}\left\|J S_{i} w_{n, i}\right\|^{2}
\end{aligned}
$$




$$
\begin{aligned}
& =\beta_{n, i}^{(1)} \phi\left(u, x_{n}\right)+\beta_{n, i}^{(2)} \phi\left(u, T_{i} x_{n}\right)+\beta_{n, i}^{(3)} \phi\left(u, S_{i} w_{n, i}\right) \\
& \leq \beta_{n, i}^{(1)} \phi\left(u, x_{n}\right)+\beta_{n, i}^{(2)} \phi\left(u, x_{n}\right)+\beta_{n, i}^{(3)} \phi\left(u, w_{n, i}\right) \\
& \leq \phi\left(u, x_{n}\right),
\end{aligned}
$$

and hence

$$
\begin{aligned}
\phi\left(u, y_{n, i}\right) & =\phi\left(u, J^{-1}\left(\alpha_{n, i} J x_{0}+\left(1-\alpha_{n, i}\right) J z_{n, i}\right)\right) \\
& =\|u\|^{2}-2\left\langle u, \alpha_{n, i} J x_{0}+\left(1-\alpha_{n, i}\right) J z_{n, i}\right\rangle+\left\|\alpha_{n, i} J x_{0}+\left(1-\alpha_{n, i}\right) J z_{n, i}\right\|^{2} \\
& \leq\|u\|^{2}-2 \alpha_{n, i}\left\langle u, J x_{0}\right\rangle-2\left(1-\alpha_{n, i}\right)\left\langle u, J z_{n, i}\right\rangle+\alpha_{n, i}\left\|x_{0}\right\|^{2}+\left(1-\alpha_{n, i}\right)\left\|z_{n, i}\right\|^{2} \\
& \leq \alpha_{n, i} \phi\left(u, x_{0}\right)+\left(1-\alpha_{n, i}\right) \phi\left(u, z_{n, i}\right) \\
& \leq \alpha_{n, i} \phi\left(u, x_{0}\right)+\left(1-\alpha_{n, i}\right) \phi\left(u, x_{n}\right) \\
& =\phi\left(u, x_{n}\right)+\alpha_{n, i}\left[\phi\left(u, x_{0}\right)-\phi\left(u, x_{n}\right)\right] \\
& \leq \phi\left(u, x_{n}\right)+\alpha_{n, i}\left(\left\|x_{0}\right\|^{2}+2\left\langle u, J x_{n}-J x_{0}\right\rangle\right) .
\end{aligned}
$$

This show that $u \in C_{n+1, i}$ for each $i \in I$. That is, $u \in C_{n}=\bigcap_{i \in I} C_{n, i}$ for all $n \geq 0$. This show that

$$
F:=\bigcap_{i \in I} F\left(T_{i}\right) \cap \bigcap_{i \in I} F\left(S_{i}\right) \cap V I(A, C) \subset C_{n}, \quad \forall n \geq 0 .
$$

Step 3. Show that $\lim _{n \rightarrow \infty} \phi\left(x_{n}, x_{0}\right)$ exists.

We note that $C_{n+1, i} \subset C_{n, i}$ for all $n \geq 0$ and for all $i \in I$. Hence

$$
C_{n+1}=\bigcap_{i \in I} C_{n+1, i} \subset C_{n}=\bigcap_{i \in I} C_{n, i}
$$

From $x_{n+1}=\prod_{C_{n+1}} x_{0} \in C_{n+1} \subset C_{n}$ and $x_{n}=\prod_{C_{n}} x_{0} \in C_{n}$, we have

$$
\phi\left(x_{n}, x_{0}\right) \leq \phi\left(x_{n+1}, x_{0}\right), \quad \forall n \geq 1 .
$$

This shows that $\left\{\phi\left(x_{n}, x_{0}\right)\right\}$ is nondecreasing. On the other hand, from Lemma 2.4, we have

$$
\phi\left(x_{n}, x_{0}\right)=\phi\left(\Pi_{C_{n}} x_{0}, x_{0}\right) \leq \phi\left(w, x_{0}\right)-\phi\left(w, x_{n}\right) \leq \phi\left(w, x_{0}\right)
$$

for each $w \in F \subset C_{n}$. This show that $\left\{\phi\left(x_{n}, x_{0}\right)\right\}$ is bounded. Consequently, $\lim _{n \rightarrow \infty} \phi\left(x_{n}, x_{0}\right)$ exists.

Step 4. Show that $\left\{x_{n}\right\}$ is a convergent sequence in $C$. 
Since $x_{m}=\Pi_{C_{m}} x_{0} \in C_{n}$ for any $m \geq n$. It follows that

$$
\begin{aligned}
\phi\left(x_{m}, x_{n}\right) & =\phi\left(x_{m}, \Pi_{C_{n}} x_{0}\right) \\
& \leq \phi\left(x_{m}, x_{0}\right)-\phi\left(\Pi_{C_{n}} x_{0}, x_{0}\right) \\
& =\phi\left(x_{m}, x_{0}\right)-\phi\left(x_{n}, x_{0}\right) .
\end{aligned}
$$

Letting $m, n \rightarrow \infty$ in (3.14), we have $\phi\left(x_{m}, x_{n}\right) \rightarrow 0$. It follows from Lemma 2.2 that

$$
\lim _{m, n \rightarrow \infty}\left\|x_{m}-x_{n}\right\|=0
$$

Hence $\left\{x_{n}\right\}$ is a Cauchy sequence in $C$. By the completeness of $E$ and the closedness of $C$, we can assume that

$$
x_{n} \longrightarrow p \in C \quad \text { as } n \longrightarrow \infty \text {. }
$$

Step 5. We show that $p \in F:=\bigcap_{i \in I} F\left(T_{i}\right) \cap \bigcap_{i \in I} F\left(S_{i}\right) \cap V I(A, C)$. that

(I) We first show that $p \in \bigcap_{i \in I} F\left(T_{i}\right) \cap \bigcap_{i \in I} F\left(S_{i}\right)$. Taking $m=n+1$ in (3.14), one arrives

$$
\lim _{n \rightarrow \infty} \phi\left(x_{n+1}, x_{n}\right)=0
$$

From Lemma 2.2, we obtain

$$
\lim _{n \rightarrow \infty}\left\|x_{n+1}-x_{n}\right\|=0
$$

Noticing that $x_{n+1}=\Pi_{C_{n+1}} x_{0}$, from the definition of $C_{n, i}$ for every $i \in I$, we obtain

$$
\phi\left(x_{n+1}, y_{n, i}\right) \leqslant \phi\left(x_{n+1}, x_{n}\right)+\alpha_{n, i}\left(\left\|x_{0}\right\|^{2}+2\left\langle u, J x_{n}-J x_{0}\right\rangle\right) .
$$

It follows from (3.17) and $\lim _{n \rightarrow \infty} \alpha_{n, i}=0$ and the fact that $\left\{J x_{n}\right\}$ is bounded that

$$
\lim _{n \rightarrow \infty} \phi\left(x_{n+1}, y_{n, i}\right)=0, \quad \forall i \in I \text {. }
$$

From Lemma 2.2, we obtain

$$
\lim _{n \rightarrow \infty}\left\|x_{n+1}-y_{n, i}\right\|=0, \quad \forall i \in I
$$

It follows from (3.18) that

$$
\lim _{n \rightarrow \infty}\left\|x_{n}-y_{n, i}\right\|=0, \quad \forall i \in I
$$


Since $J$ is uniformly norm-to-norm continuity on bounded sets, for every $i \in I$, one has

$$
\lim _{n \rightarrow \infty}\left\|J x_{n}-J y_{n, i}\right\|=\lim _{n \rightarrow \infty}\left\|J x_{n+1}-J x_{n}\right\|=0, \quad \forall i \in I .
$$

For every $i \in I$, we obtain from the properties of $\phi$ that

$$
\begin{aligned}
\phi\left(z_{n, i}, x_{n}\right) & =\phi\left(z_{n, i}, y_{n, i}\right)+\phi\left(y_{n, i}, x_{n}\right)+2\left\langle z_{n, i}-y_{n, i}, J y_{n, i}-J x_{n}\right\rangle \\
& \leq \phi\left(z_{n, i}, y_{n, i}\right)+\phi\left(y_{n, i}, x_{n}\right)+2\left\|z_{n, i}-y_{n, i}\right\|\left\|J y_{n, i}-J x_{n}\right\|
\end{aligned}
$$

On the other hand, for all $i \in I$, we have

$$
\begin{aligned}
\phi\left(z_{n, i}, y_{n, i}\right) & =\left\|z_{n, i}\right\|^{2}-2\left\langle z_{n, i}, \alpha_{n, i} J x_{0}+\left(1-\alpha_{n, i}\right) J z_{n, i}\right\rangle+\left\|\alpha_{n, i} J x_{0}+\left(1-\alpha_{n, i}\right) J z_{n, i}\right\|^{2} \\
& \leq\left\|z_{n, i}\right\|^{2}-2 \alpha_{n, i}\left\langle z_{n, i} J x_{0}\right\rangle-2\left(1-\alpha_{n, i}\right)\left\langle z_{n, i}, J z_{n, i}\right\rangle+\alpha_{n, i}\left\|x_{0}\right\|^{2}+\left(1-\alpha_{n, i}\right)\left\|z_{n, i}\right\|^{2} \\
& =\alpha_{n, i}\left(\left\|z_{n, i}\right\|^{2}-2\left\langle z_{n, i}, J x_{0}\right\rangle+\left\|x_{0}\right\|^{2}\right)=\alpha_{n, i} \phi\left(z_{n, i}, x_{0}\right) .
\end{aligned}
$$

It follows form (ii) that

$$
\lim _{n \rightarrow \infty} \phi\left(z_{n, i}, y_{n, i}\right)=0, \quad \forall i \in I
$$

Notice that

$$
\begin{aligned}
\phi\left(y_{n, i}, x_{n}\right)= & \left\|y_{n, i}\right\|^{2}-2\left\langle y_{n, i}, J x_{n}\right\rangle+\left\|x_{n}\right\|^{2} \\
= & \left\|y_{n, i}\right\|^{2}-2\left\langle y_{n, i}, J x_{n}\right\rangle+\left\|x_{n}\right\|^{2}+\left\|x_{n+1}\right\|^{2}-\left\|x_{n+1}\right\|^{2} \\
& -2\left\langle x_{n+1}, J y_{n, i}\right\rangle+2\left\langle x_{n+1}, J y_{n, i}\right\rangle \\
= & \phi\left(x_{n+1}, y_{n, i}\right)-2\left\langle y_{n, i}, J x_{n}\right\rangle+\left\|x_{n}\right\|^{2}-\left\|x_{n+1}\right\|^{2}+2\left\langle x_{n+1}, J y_{n, i}\right\rangle \\
= & \phi\left(x_{n+1}, y_{n, i}\right)+\left(\left\|x_{n}-x_{n+1}\right\|\right)\left(\left\|x_{n}\right\|+\left\|x_{n+1}\right\|\right) \\
& -2\left\langle y_{n, i}, J x_{n}-J y_{n, i}\right\rangle-2\left\langle y_{n, i}, J y_{n, i}\right\rangle+2\left\langle x_{n+1}, J y_{n, i}\right\rangle \\
= & \phi\left(x_{n+1}, y_{n, i}\right)+\left(\left\|x_{n}-x_{n+1}\right\|\right)\left(\left\|x_{n}\right\|+\left\|x_{n+1}\right\|\right) \\
& +2\left\langle y_{n, i}, J y_{n, i}-J x_{n}\right\rangle+2\left\langle x_{n+1}-y_{n, i}, J y_{n, i}\right\rangle \\
\leq & \phi\left(x_{n+1}, y_{n, i}\right)+\left(\left\|x_{n}-x_{n+1}\right\|\right)\left(\left\|x_{n}\right\|+\left\|x_{n+1}\right\|\right) \\
& +2\left\|y_{n, i}\right\|\left\|J y_{n, i}-J x_{n}\right\|+2\left\|x_{n+1}-y_{n, i}\right\|\left\|J y_{n, i}\right\| .
\end{aligned}
$$

Applying (3.18), (3.20), (3.21), and (3.23) to the last inequality, we obtain

$$
\lim _{n \rightarrow \infty} \phi\left(y_{n, i}, x_{n}\right)=0, \quad \forall i \in I .
$$


Combining (3.26) with (3.28) in (3.24), we have

$$
\lim _{n \rightarrow \infty} \phi\left(z_{n, i}, x_{n}\right)=0, \quad \forall i \in I
$$

From Lemma 2.2, we have

$$
\lim _{n \rightarrow \infty}\left\|z_{n, i}-x_{n}\right\|=0, \quad \forall i \in I
$$

Since $J$ is uniformly norm-to-norm continuity on bounded sets, for every $i \in I$, one has

$$
\lim _{n \rightarrow \infty}\left\|J z_{n, i}-J x_{n}\right\|=0, \quad \forall i \in I
$$

Let $r=\sup _{n \geq 1}\left\{\left\|x_{n}\right\|,\left\|T_{i} x_{n}\right\|,\left\|S_{i} x_{n}\right\|\right\}$ for every $i \in I$. Therefore Lemma 2.7 implies that there exists a continuous strictly increasing convex function $g:[0, \infty) \rightarrow[0, \infty)$ satisfying $g(0)=0$ and (2.7).

Case I. Assume that (a) holds. Applying (2.7), we can calculate

$$
\begin{aligned}
\phi\left(u, z_{n, i}\right)= & \phi\left(u, J^{-1}\left(\beta_{n, i}^{(1)} J x_{n}+\beta_{n, i}^{(2)} J T_{i} x_{n}+\beta_{n, i}^{(3)} J S_{i} w_{n, i}\right)\right) \\
= & \|u\|^{2}-2\left\langle u, \beta_{n, i}^{(1)} J x_{n}+\beta_{n, i}^{(2)} J T_{i} x_{n}+\beta_{n, i}^{(3)} J S_{i} w_{n, i}\right\rangle \\
& +\left\|\beta_{n, i}^{(1)} J x_{n}+\beta_{n, i}^{(2)} J T_{i} x_{n}+\beta_{n, i}^{(3)} J S_{i} w_{n, i}\right\|^{2} \\
\leq & \|u\|^{2}-2 \beta_{n, i}^{(1)}\left\langle u, J x_{n}\right\rangle-2 \beta_{n, i}^{(2)}\left\langle u, J T_{i} x_{n}\right\rangle-2 \beta_{n, i}^{(2)}\left\langle u, J S_{i} w_{n, i}\right\rangle \\
& +\beta_{n, i}^{(1)}\left\|x_{n}\right\|^{2}+\beta_{n, i}^{(2)}\left\|T_{i} x_{n}\right\|^{2}+\beta_{n, i}^{(3)}\left\|S_{i} w_{n, i}\right\|^{2}-\beta_{n, i}^{(1)} \beta_{n, i}^{(2)} g\left(\left\|J x_{n}-J T_{i} x_{n}\right\|\right) \\
= & \beta_{n, i}^{(1)} \phi\left(u, x_{n}\right)+\beta_{n, i}^{(2)} \phi\left(u, T_{i} x_{n}\right)+\beta_{n, i}^{(3)} \phi\left(u, S_{i} w_{n, i}\right)-\beta_{n, i}^{(1)} \beta_{n, i}^{(2)} g\left(\left\|J x_{n}-J T_{i} x_{n}\right\|\right) \\
\leq & \beta_{n, i}^{(1)} \phi\left(u, x_{n}\right)+\beta_{n, i}^{(2)} \phi\left(u, x_{n}\right)+\beta_{n, i}^{(3)} \phi\left(u, w_{n, i}\right)-\beta_{n, i}^{(1)} \beta_{n, i}^{(2)} g\left(\left\|J x_{n}-J T_{i} x_{n}\right\|\right) \\
\leq & \beta_{n, i}^{(1)} \phi\left(u, x_{n}\right)+\beta_{n, i}^{(2)} \phi\left(u, x_{n}\right)+\beta_{n, i}^{(3)} \phi\left(u, x_{n}\right)-\beta_{n, i}^{(1)} \beta_{n, i}^{(2)} g\left(\left\|J x_{n}-J T_{i} x_{n}\right\|\right) \\
= & \phi\left(u, x_{n}\right)-\beta_{n, i}^{(1)} \beta_{n, i}^{(2)} g\left(\left\|J x_{n}-J T_{i} x_{n}\right\|\right) .
\end{aligned}
$$

This implies that

$$
\beta_{n, i}^{(1)} \beta_{n, i}^{(2)} g\left(\left\|J x_{n}-J T_{i} x_{n}\right\|\right) \leq \phi\left(u, x_{n}\right)-\phi\left(u, z_{n, i}\right), \quad \forall i \in I
$$

On the other hand, for every $i \in I$, one has

$$
\begin{aligned}
\phi\left(u, x_{n}\right)-\phi\left(u, z_{n, i}\right) & =\left\|x_{n}\right\|^{2}-\left\|z_{n, i}\right\|^{2}-2\left\langle u, J x_{n}-J z_{n, i}\right\rangle \\
& \leq\left\|x_{n}-z_{n, i}\right\|\left(\left\|x_{n}\right\|+\left\|z_{n, i}\right\|\right)+2\|u\|\left\|J x_{n}-J z_{n, i}\right\| .
\end{aligned}
$$


It follows from (3.30) and (3.31) that

$$
\phi\left(u, x_{n}\right)-\phi\left(u, z_{n, i}\right) \longrightarrow 0 \quad \text { as } n \longrightarrow \infty, \forall i \in I \text {. }
$$

Applying $\lim \inf _{n \rightarrow \infty} \beta_{n, i}^{(1)} \beta_{n, i}^{(2)}>0$ and (3.35) in (3.33) we get

$$
g\left(\left\|J x_{n}-J T_{i} x_{n}\right\|\right) \longrightarrow 0 \text { as } n \longrightarrow \infty, \forall i \in I .
$$

It follows from the property of $g$ that

$$
\left\|J x_{n}-J T_{i} x_{n}\right\| \longrightarrow 0 \text { as } n \longrightarrow \infty, \forall i \in I .
$$

Since $J^{-1}$ is also uniformly norm-to-norm continuity on bounded sets, for every $i \in I$, one has

$$
\lim _{n \rightarrow \infty}\left\|x_{n}-T_{i} x_{n}\right\|=0, \quad \forall i \in I
$$

In a similar way, one has

$$
\lim _{n \rightarrow \infty}\left\|x_{n}-S_{i} w_{n, i}\right\|=0, \quad \forall i \in I
$$

On the other hand, we observe from (3.7) that

$$
\begin{aligned}
\phi\left(u, z_{n, i}\right)= & \phi\left(u, J^{-1}\left(\beta_{n, i}^{(1)} J x_{n}+\beta_{n, i}^{(2)} J T_{i} x_{n}+\beta_{n, i}^{(3)} J S_{i} w_{n, i}\right)\right) \\
= & \|u\|^{2}-2\left\langle u, \beta_{n, i}^{(1)} J x_{n}+\beta_{n, i}^{(2)} J T_{i} x_{n}+\beta_{n, i}^{(3)} J S_{i} w_{n, i}\right\rangle \\
& +\left\|\beta_{n, i}^{(1)} J x_{n}+\beta_{n, i}^{(2)} J T_{i} x_{n}+\beta_{n, i}^{(3)} J S_{i} w_{n, i}\right\|^{2} \\
\leq & \|u\|^{2}-2 \beta_{n, i}^{(1)}\left\langle u, J x_{n}\right\rangle-2 \beta_{n, i}^{(2)}\left\langle u, J T_{i} x_{n}\right\rangle-2 \beta_{n, i}^{(2)}\left\langle u, J S_{i} w_{n, i}\right\rangle \\
& +\beta_{n, i}^{(1)}\left\|J x_{n}\right\|^{2}+\beta_{n, i}^{(2)}\left\|J T_{i} x_{n}\right\|^{2}+\beta_{n, i}^{(3)}\left\|J S_{i} w_{n, i}\right\|^{2}-\beta_{n, i}^{(1)} \beta_{n, i}^{(2)} g\left(\left\|J x_{n}-J T_{i} x_{n}\right\|\right) \\
= & \beta_{n, i}^{(1)} \phi\left(u, x_{n}\right)+\beta_{n, i}^{(2)} \phi\left(u, T_{i} x_{n}\right)+\beta_{n, i}^{(3)} \phi\left(u, S_{i} w_{n, i}\right)-\beta_{n, i}^{(1)} \beta_{n, i}^{(2)} g\left(\left\|J x_{n}-J T_{i} x_{n}\right\|\right) \\
\leq & \beta_{n, i}^{(1)} \phi\left(u, x_{n}\right)+\beta_{n, i}^{(2)} \phi\left(u, x_{n}\right)+\beta_{n, i}^{(3)} \phi\left(u, w_{n, i}\right)-\beta_{n, i}^{(1)} \beta_{n, i}^{(2)} g\left(\left\|J x_{n}-J T_{i} x_{n}\right\|\right) \\
\leq & \beta_{n, i}^{(1)} \phi\left(u, x_{n}\right)+\beta_{n, i}^{(2)} \phi\left(u, x_{n}\right)+\beta_{n, i}^{(3)}\left[\phi\left(u, x_{n}\right)+2 \lambda_{n, i}\left(\frac{2}{c^{2}} \lambda_{n, i}-\alpha\right)\left\|A x_{n}-A u\right\|^{2}\right] \\
= & \phi\left(u, x_{n}\right)+2 \beta_{n, i}^{(3)} \lambda_{n, i}\left(\frac{2}{c^{2}} \lambda_{n, i}-\alpha\right)\left\|A x_{n}-A u\right\|^{2} .
\end{aligned}
$$


Hence

$$
2 a\left(\alpha-\frac{2}{c^{2}} b\right)\left\|A x_{n}-A u\right\|^{2} \leq \phi\left(u, x_{n}\right)-\phi\left(u, z_{n, i}\right) .
$$

Using (3.35), we can conclude that

$$
\lim _{n \rightarrow \infty}\left\|A x_{n}-A u\right\|=0, \quad \forall i \in I .
$$

From (3.6), we can calculate

$$
\begin{aligned}
\phi\left(x_{n}, w_{n, i}\right)= & \phi\left(x_{n}, \Pi_{C} v_{n, i}\right) \\
\leq & \phi\left(x_{n}, v_{n, i}\right) \\
= & \phi\left(x_{n}, J^{-1}\left(J x_{n}-\lambda_{n, i} A x_{n}\right)\right) \\
= & V\left(x_{n}, J x_{n}-\lambda_{n, i} A x_{n}\right) \\
\leq & V\left(x_{n},\left(J x_{n}-\lambda_{n, i} A x_{n}\right)+\lambda_{n, i} A x_{n}\right) \\
& -2\left\langle J^{-1}\left(J x_{n}-\lambda_{n, i} A x_{n}\right)-u, \lambda_{n, i} A x_{n}\right\rangle \\
= & V\left(x_{n}, J x_{n}\right)+2\left\langle v_{n, i}-x_{n},-\lambda_{n, i} A x_{n}\right\rangle \\
= & \phi\left(x_{n}, x_{n}\right)+2\left\langle v_{n, i}-x_{n},-\lambda_{n, i} A x_{n}\right\rangle \\
= & 2\left\langle v_{n, i}-x_{n},-\lambda_{n, i} A x_{n}\right\rangle \\
\leq & \frac{4}{c^{2}} \lambda_{n, i}^{2}\left\|A x_{n}-A u\right\| .
\end{aligned}
$$

It follows from (3.42) and the fact that $\left\{\lambda_{n, i}\right\}$ is bounded that

$$
\lim _{n \rightarrow \infty} \phi\left(x_{n}, w_{n, i}\right)=0, \quad \forall i \in I
$$

From Lemma 2.2, we have

$$
\lim _{n \rightarrow \infty}\left\|x_{n}-w_{n, i}\right\|=0, \quad \forall i \in I
$$

Hence $w_{n, i} \rightarrow p$ as $n \rightarrow \infty$ for each $i \in I$. From (3.39) and (3.45), we have

$$
\lim _{n \rightarrow \infty}\left\|w_{n, i}-S_{i} w_{n, i}\right\|=0, \quad \forall i \in I
$$

The closedness of $T_{i}$ and $S_{i}$ implies that $p \in \bigcap_{i \in I} F\left(T_{i}\right) \cap \bigcap_{i \in I} F\left(S_{i}\right)$. 
Case II. Assume that (b) holds. We observe that

$$
\begin{aligned}
\phi\left(u, z_{n, i}\right)= & \phi\left(u, J^{-1}\left(\beta_{n, i}^{(1)} J x_{n}+\beta_{n, i}^{(2)} J T_{i} x_{n}+\beta_{n, i}^{(3)} J S_{i} w_{n, i}\right)\right) \\
= & \|u\|^{2}-2\left\langle u, \beta_{n, i}^{(1)} J x_{n}+\beta_{n, i}^{(2)} J T_{i} x_{n}+\beta_{n, i}^{(3)} J S_{i} w_{n, i}\right\rangle \\
& +\left\|\beta_{n, i}^{(1)} J x_{n}+\beta_{n, i}^{(2)} J T_{i} x_{n}+\beta_{n, i}^{(3)} J S_{i} w_{n, i}\right\|^{2} \\
\leq & \|u\|^{2}-2 \beta_{n, i}^{(1)}\left\langle u, J x_{n}\right\rangle-2 \beta_{n, i}^{(2)}\left\langle u, J T_{i} x_{n}\right\rangle-2 \beta_{n, i}^{(2)}\left\langle u, J S_{i} w_{n, i}\right\rangle \\
& +\beta_{n, i}^{(1)}\left\|J x_{n}\right\|^{2}+\beta_{n, i}^{(2)}\left\|J T_{i} x_{n}\right\|^{2}+\beta_{n, i}^{(3)}\left\|J S_{i} w_{n, i}\right\|^{2}-\beta_{n, i}^{(2)} \beta_{n, i}^{(3)} g\left(\left\|J S_{i} w_{n, i}-J T_{i} x_{n}\right\|\right) \\
= & \beta_{n, i}^{(1)} \phi\left(u, x_{n}\right)+\beta_{n, i}^{(2)} \phi\left(u, T_{i} x_{n}\right)+\beta_{n, i}^{(3)} \phi\left(u, S_{i} w_{n, i}\right)-\beta_{n, i}^{(2)} \beta_{n, i}^{(3)} g\left(\left\|J S_{i} w_{n, i}-J T_{i} x_{n}\right\|\right) \\
\leq & \beta_{n, i}^{(1)} \phi\left(u, x_{n}\right)+\beta_{n, i}^{(2)} \phi\left(u, x_{n}\right)+\beta_{n, i}^{(3)} \phi\left(u, w_{n, i}\right)-\beta_{n, i}^{(2)} \beta_{n, i}^{(3)} g\left(\left\|J S_{i} w_{n, i}-J T_{i} x_{n}\right\|\right) \\
\leq & \beta_{n, i}^{(1)} \phi\left(u, x_{n}\right)+\beta_{n, i}^{(2)} \phi\left(u, x_{n}\right)+\beta_{n, i}^{(3)} \phi\left(u, x_{n}\right)-\beta_{n, i}^{(2)} \beta_{n, i}^{(3)} g\left(\left\|J S_{i} w_{n, i}-J T_{i} x_{n}\right\|\right) \\
= & \phi\left(u, x_{n}\right)-\beta_{n, i}^{(2)} \beta_{n, i}^{(3)} g\left(\left\|J S_{i} w_{n, i}-J T_{i} x_{n}\right\|\right) .
\end{aligned}
$$

This implies that

$$
\beta_{n, i}^{(2)} \beta_{n, i}^{(3)} g\left(\left\|J S_{i} w_{n, i}-J T_{i} x_{n}\right\|\right) \leq \phi\left(u, x_{n}\right)-\phi\left(u, z_{n, i}\right), \quad \forall i \in I
$$

On the other hand, for every $i \in I$, one has

$$
\begin{aligned}
\phi\left(u, x_{n}\right)-\phi\left(u, z_{n, i}\right) & =\left\|x_{n}\right\|^{2}-\left\|z_{n, i}\right\|^{2}-2\left\langle u, J x_{n}-J z_{n, i}\right\rangle \\
& \leq\left\|x_{n}-z_{n, i}\right\|\left(\left\|x_{n}\right\|+\left\|z_{n, i}\right\|\right)+2\|u\|\left\|J x_{n}-J z_{n, i}\right\| .
\end{aligned}
$$

It follows from (3.30) and (3.31) that

$$
\phi\left(u, x_{n}\right)-\phi\left(u, z_{n, i}\right) \longrightarrow 0 \quad \text { as } n \longrightarrow \infty, \forall i \in I
$$

Applying $\liminf \operatorname{in}_{n \rightarrow \infty} \beta_{n, i}^{(2)} \beta_{n, i}^{(3)}>0$ and (3.50) we get

$$
g\left(\left\|J S_{i} w_{n, i}-J T_{i} x_{n}\right\|\right) \longrightarrow 0 \text { as } n \longrightarrow \infty, \forall i \in I .
$$

It follows from the property of $g$ that

$$
\left\|J S_{i} w_{n, i}-J T_{i} x_{n}\right\| \longrightarrow 0 \text { as } n \longrightarrow \infty, \forall i \in I .
$$


Since $J^{-1}$ is also uniformly norm-to-norm continuity on bounded sets, for every $i \in I$, one has

$$
\lim _{n \rightarrow \infty}\left\|T_{i} x_{n}-S_{i} w_{n, i}\right\|=0, \quad \forall i \in I
$$

On the other hand, we can calculate

$$
\begin{aligned}
\phi\left(T_{i} x_{n}, z_{n, i}\right)= & \phi\left(T_{i} x_{n}, J^{-1}\left(\beta_{n, i}^{(1)} J x_{n}+\beta_{n, i}^{(2)} J T_{i} x_{n}+\beta_{n, i}^{(3)} J S_{i} w_{n, i}\right)\right) \\
= & \left\|T_{i} x_{n}\right\|^{2}-2\left\langle T_{i} x_{n}, \beta_{n, i}^{(1)} J x_{n}+\beta_{n, i}^{(2)} J T_{i} x_{n}+\beta_{n, i}^{(3)} J S_{i} w_{n, i}\right\rangle \\
& \left.+\| \beta_{n, i}^{(1)} J x_{n}+\beta_{n, i}^{(2)} J T_{i} x_{n}+\beta_{n, i}^{(3)} J S_{i} w_{n, i}\right) \|^{2} \\
\leq & \left\|T_{i} x_{n}\right\|^{2}-2 \beta_{n, i}^{(1)}\left\langle T_{i} x_{n}, J x_{n}\right\rangle-2 \beta_{n, i}^{(2)}\left\langle T_{i} x_{n} J T_{i} x_{n}\right\rangle-2 \beta_{n, i}^{(3)}\left\langle T_{i} x_{n} J S_{i} w_{n, i}\right\rangle \\
& +\beta_{n, i}^{(1)}\left\|x_{n}\right\|^{2}+\beta_{n, i}^{(2)}\left\|T_{i} x_{n}\right\|^{2}+\beta_{n, i}^{(3)}\left\|S_{i} w_{n, i}\right\|^{2} \\
\leq & \beta_{n, i}^{(1)} \phi\left(T_{i} x_{n}, x_{n}\right)+\beta_{n, i}^{(3)} \phi\left(T_{i} x_{n}, S_{i} w_{n, i}\right) .
\end{aligned}
$$

Observe that

$$
\begin{aligned}
\phi\left(T_{i} x_{n}, S_{i} w_{n, i}\right) & =\left\|T_{i} x_{n}\right\|^{2}-2\left\langle T_{i} x_{n}, J S_{i} w_{n, i}\right\rangle+\left\|S_{i} w_{n, i}\right\|^{2} \\
& =\left\|T_{i} x_{n}\right\|^{2}-2\left\langle T_{i} x_{n}, J T_{i} x_{n}\right\rangle+2\left\langle T_{i} x_{n}, J T_{i} x_{n}-J S_{i} w_{n, i}\right\rangle+\left\|S_{i} w_{n, i}\right\|^{2} \\
& \leq\left\|S_{i} w_{n, i}\right\|^{2}-\left\|T_{i} x_{n}\right\|^{2}+2\left\|T_{i} x_{n}\right\|\left\|J T_{i} x_{n}-J S_{i} w_{n, i}\right\| \\
& \leq\left\|S_{i} w_{n, i}-T_{i} x_{n}\right\|\left(\left\|S_{i} w_{n, i}\right\|+\left\|T_{i} x_{n}\right\|\right)+2\left\|T_{i} x_{n}\right\|\left\|J T_{i} x_{n}-J S_{i} w_{n, i}\right\| .
\end{aligned}
$$

It follows from (3.52) and (3.53) that

$$
\lim _{n \rightarrow \infty} \phi\left(T_{i} x_{n}, S_{i} w_{n, i}\right)=0, \quad \forall i \in I
$$

Applying $\lim _{n \rightarrow \infty} \beta_{n, i}^{(1)}=0$ and (3.56) and the fact that $\left\{\phi\left(T_{i} x_{n}, x_{n}\right)\right\}$ is bounded to (3.54), we obtain

$$
\lim _{n \rightarrow \infty} \phi\left(T_{i} x_{n}, z_{n, i}\right)=0, \quad \forall i \in I
$$

From Lemma 2.2, one obtains

$$
\lim _{n \rightarrow \infty}\left\|T_{i} x_{n}-z_{n, i}\right\|=0, \quad \forall i \in I .
$$


We observe that

$$
\left\|T_{i} x_{n}-x_{n}\right\| \leq\left\|T_{i} x_{n}-z_{n, i}\right\|+\left\|z_{n, i}-x_{n}\right\| .
$$

It follows from (3.30) and (3.58) that

$$
\lim _{n \rightarrow \infty}\left\|T_{i} x_{n}-x_{n}\right\|=0, \quad \forall i \in I .
$$

By the same proof as in Case I, we obtain that

$$
\lim _{n \rightarrow \infty}\left\|x_{n}-w_{n, i}\right\|=0, \quad \forall i \in I
$$

Hence $w_{n, i} \rightarrow p$ as $n \rightarrow \infty$ for each $i \in I$ and

$$
\lim _{n \rightarrow \infty}\left\|J x_{n}-J w_{n, i}\right\|=0, \quad \forall i \in I
$$

Combining (3.53), (3.60), and (3.61), we also have

$$
\lim _{n \rightarrow \infty}\left\|S_{i} w_{n, i}-w_{n, i}\right\|=0, \quad \forall i \in I .
$$

It follows from the closedness of $T_{i}$ and $S_{i}$ that $p \in \bigcap_{i \in I} F\left(T_{i}\right) \cap \bigcap_{i \in I} F\left(S_{i}\right)$.

(II) Now, we show that $p \in V I(A, C)$.

Let $T \subset E \times E^{*}$ be an operator defined by

$$
T v= \begin{cases}A v+N_{C}(v), & v \in C, \\ \emptyset, & v \notin C .\end{cases}
$$

By Lemma 2.8, we have that $T$ is maximal monotone and $T^{-1} 0=V I(A, C)$. Let $(v, w) \in G(T)$. Since $w \in T v=A v+N_{C}(v)$, we obtain that $w-A v \in N_{C}(v)$. From $x_{n}=\Pi_{C_{n}} x_{0} \subset C_{n} \subset C$, we have

$$
\left\langle v-x_{n}, w-A v\right\rangle \geq 0
$$

Since $A$ is $\alpha$-inverse strongly monotone, we can calculate

$$
\begin{aligned}
\left\langle v-x_{n}, w\right\rangle & \geq\left\langle v-x_{n}, A v\right\rangle \\
& =\left\langle v-x_{n}, A v-A x_{n}\right\rangle+\left\langle v-x_{n}, A x_{n}\right\rangle \\
& \geq\left\langle v-x_{n}, A x_{n}\right\rangle .
\end{aligned}
$$


From $w_{n, i}=\Pi_{C} J^{-1}\left(J x_{n}-\lambda_{n, i} A x_{n}\right)$ and by Lemma 2.3, we have

$$
\left\langle v-w_{n, i}, J w_{n, i}-J x_{n}-\lambda_{n, i} A x_{n}\right\rangle \geq 0 .
$$

This implies that

$$
\left\langle v-w_{n, i}, \frac{J x_{n}-J w_{n, i}}{\lambda_{n, i}}-A x_{n}\right\rangle \leq 0
$$

Since $A$ is $\alpha$-inverse strongly monotone, we have also that $A$ is $1 / \alpha$-Lipschitzian. Hence

$$
\begin{aligned}
\left\langle v-x_{n}, w\right\rangle \geq & \left\langle v-x_{n}, A x_{n}\right\rangle+\left\langle v-w_{n, i}, \frac{J x_{n}-J w_{n, i}}{\lambda_{n, i}}-A x_{n}\right\rangle \\
= & \left\langle v-w_{n, i}, A x_{n}\right\rangle+\left\langle w_{n, i}-x_{n}, A x_{n}\right\rangle \\
& -\left\langle v-w_{n, i}, A x_{n}\right\rangle+\left\langle v-w_{n, i}, \frac{J x_{n}-J w_{n, i}}{\lambda_{n, i}}\right\rangle \\
= & \left\langle w_{n, i}-x_{n}, A x_{n}\right\rangle+\left\langle v-w_{n, i}, \frac{J x_{n}-J w_{n, i}}{\lambda_{n, i}}\right\rangle \\
\geq & -\left\|w_{n, i}-x_{n}\right\|\left\|A x_{n}\right\|-\left\|v-w_{n, i}\right\|\left\|\frac{J x_{n}-J w_{n, i}}{a}\right\|
\end{aligned}
$$

for all $n \geq 0$. By Taking the limit as $n \rightarrow \infty$ and by (3.61) and (3.62), we obtain $\langle v-p, w\rangle \geq 0$. By the maximality of $T$ we obtain $p \in T^{-1} 0$ and hence $p \in V I(A, C)$. Hence $p \in F$.

Step 6. Finally, we show that $p=\Pi_{F} x_{0}$.

From $x_{n}=\prod_{C_{n}} x_{0}$, we have

$$
\left\langle J x_{0}-J x_{n}, x_{n}-z\right\rangle \geq 0, \quad \forall z \in C_{n} .
$$

Since $F \subset C_{n}$, we also have

$$
\left\langle J x_{0}-J x_{n}, x_{n}-u\right\rangle \geq 0, \quad \forall u \in F .
$$

By taking limit in (3.71), we obtain that

$$
\left\langle J x_{0}-J p, p-u\right\rangle \geq 0, \quad \forall u \in F .
$$

By Lemma 2.3, we can conclude that $p=\Pi_{F} x_{0}$. This completes the proof. 
Remark 3.2. Theorem 3.1 improves and extends main results of Iiduka and Takahashi [17], Martinez-Yanes and $\mathrm{Xu}$ [23], Matsushita and Takahashi [13], Plubtieng and Ungchittrakool [14], Qin and Su [15], and Qin et al. [25] because it can be applied to solving the problem of finding the common element of the set of common fixed points of two families of quasi- $\phi$ nonexpansive mappings and the set of solutions of the variational inequality for an inversestrongly monotone operator.

\section{Applications}

From Theorem 3.1 we can obtain some new and interesting strong convergence theorems. Now we give some examples as follows.

If $\beta_{n, i}^{(1)}=0$ for all $n \geq 0, T_{i}=S_{i}$ for all $i \in I$ and $A=0$ in Theorem 3.1, then we have the following result.

Corollary 4.1. Let $E$ be a uniformly convex and uniformly smooth Banach space, and let $C$ be a nonempty closed convex subset of $E$. Let $\left\{T_{i}\right\}_{i \in I}$ be a family of closed quasi- $\phi$-nonexpansive mappings of $C$ into itself with $F:=\bigcap_{i \in I} F\left(T_{i}\right)$ being nonempty, where $I$ is an index set. Let $\left\{x_{n}\right\}$ be a sequence generated by the following manner:

$$
\begin{gathered}
x_{0} \in C \text { chosen arbitrary, } \\
C_{1, i}=C, \quad C_{1}=\bigcap_{i=1}^{\infty} C_{1, i}, \quad x_{1}=\prod_{C_{1}}\left(x_{0}\right) \quad \forall i \in I, \\
y_{n, i}=J^{-1}\left(\alpha_{n, i} J x_{0}+\left(1-\alpha_{n, i}\right) J T_{i} x_{n}\right), \\
C_{n+1, i}=\left\{u \in C_{n, i}: \phi\left(u, y_{n, i}\right) \leqslant \phi\left(u, x_{n}\right)+\alpha_{n, i}\left(\left\|x_{0}\right\|^{2}+2\left\langle u, J x_{n}-J x_{0}\right\rangle\right)\right\}, \\
C_{n+1}=\bigcap_{i \in I} C_{n+1, i}, \\
x_{n+1}=\prod_{C_{n+1}} x_{0}, \quad \forall n \geq 0,
\end{gathered}
$$

where $J$ is the duality mapping on $E$, and $\left\{\alpha_{n, i}\right\}$ is a sequence in $(0,1)$ such that $\lim _{\sup } \operatorname{su}_{n \rightarrow \infty} \alpha_{n, i}=$ 0 , for all $i \in I$. Then the sequence $\left\{x_{n}\right\}$ converges strongly to $\Pi_{F} x_{0}$, where $\Pi_{F}$ is the generalized projection from $C$ onto $F$.

Now we consider the problem of finding a zero point of an inverse-strongly monotone operator of $E$ into $E^{*}$. Assume that $A$ satisfies the following conditions:

(C1) $A$ is $\alpha$-inverse-strongly monotone,

(C2) $A^{-1} 0=\{u \in E: A u=0\} \neq \emptyset$.

Corollary 4.2. Let E be a 2 uniformly convex and uniformly smooth Banach space. Let $A$ be an operator of $E$ into $E^{*}$ satisfying $(C 1)$ and (C2), and let $\left\{S_{i}\right\}_{i \in I}$ and $\left\{T_{i}\right\}_{i \in I}$ be two families of closed 
quasi- $\phi$-nonexpansive mappings of $E$ into itself with $F:=\bigcap_{i \in I} F\left(T_{i}\right) \cap \bigcap_{i \in I} F\left(S_{i}\right) \cap A^{-1} 0$ being nonempty, where I is an index set. Let $\left\{x_{n}\right\}$ be a sequence generated by the following manner:

$$
\begin{gathered}
x_{0} \in E \text { chosen arbitrary, } \\
C_{1, i}=E, \quad C_{1}=\bigcap_{i=1}^{\infty} C_{1, i} \quad x_{1}=\prod_{C_{1}}\left(x_{0}\right) \quad \forall i \in I, \\
w_{n, i}=J^{-1}\left(J x_{n}-\lambda_{n, i} A x_{n}\right), \\
z_{n, i}=J^{-1}\left(\beta_{n, i}^{(1)} J x_{n}+\beta_{n, i}^{(2)} J T_{i} x_{n}+\beta_{n, i}^{(3)} J S_{i} w_{n, i}\right), \\
y_{n, i}=J^{-1}\left(\alpha_{n, i} J x_{0}+\left(1-\alpha_{n, i}\right) J z_{n, i}\right), \\
C_{n+1, i}=\left\{u \in C_{n, i}: \phi\left(u, y_{n, i}\right) \leqslant \phi\left(u, x_{n}\right)+\alpha_{n, i}\left(\left\|x_{0}\right\|^{2}+2\left\langle u, J x_{n}-J x_{0}\right\rangle\right)\right\}, \\
C_{n+1}=\bigcap_{i \in I} C_{n+1, i}, \\
x_{n+1}=\prod_{C_{n+1}} x_{0}, \quad \forall n \geq 0,
\end{gathered}
$$

where $J$ is the duality mapping on $E$, and $\left\{\lambda_{n, i}\right\},\left\{\alpha_{n, i}\right\}$, and $\left\{\beta_{n, i}^{(j)}\right\}(j=1,2,3)$ are sequences in $(0,1)$ such that

(i) $\lim _{n \rightarrow \infty} \alpha_{n, i}=0$ for all $i \in I$;

(ii) for all $i \in I,\left\{\lambda_{n, i}\right\} \subset[a, b]$ for some $a, b$ with $0<a<b<c^{2} \alpha / 2$, where $1 / c$ is the 2 uniformly convexity constant of $E$;

(iii) $\beta_{n, i}^{(1)}+\beta_{n, i}^{(2)}+\beta_{n, i}^{(3)}=1$ for all $i \in I$ and if one of the following conditions is satisfied:

(a) $\liminf \operatorname{in}_{n \rightarrow \infty} \beta_{n, i}^{(1)} \beta_{n, i}^{(l)}>0$ for all $l=2,3$ and for all $i \in I$,

(b) $\liminf _{n \rightarrow \infty} \beta_{n, i}^{(2)} \beta_{n, i}^{(3)}>0$ and $\lim _{n \rightarrow \infty} \beta_{n, i}^{(1)}=0$ for all $i \in I$.

Then the sequence $\left\{x_{n}\right\}$ converges strongly to $\Pi_{F} x_{0}$, where $\Pi_{F}$ is the generalized projection from $C$ onto $F$.

Proof. Setting $C=E$ in Theorem 3.1, we get that $\Pi_{E}$ is the identity mapping, that is, $\Pi_{E} x=x$ for all $x \in E$. We also have $V I(A, E)=A^{-1} 0$. From Theorem 3.1, we can obtain the desired conclusion easily.

Let $X$ be a nonempty closed convex cone in $E$, and let $A$ be an operator from $X$ into $E^{*}$. We define its polar in $E^{*}$ to be the set

$$
X^{*}=\left\{y^{*} \in E^{*}:\left\langle x, y^{*}\right\rangle \geq 0 \forall x \in X\right\}
$$

Then an element $x$ in $X$ is called a solution of the complementarity problem if

$$
A x \in X^{*}, \quad\langle x, A x\rangle=0 .
$$


The set of all solutions of the complementarity problem is denoted by $C P(A, X)$. Several problems arising in different fields, such as mathematical programming, game theory, mechanics, and geometry, are to find solutions of the complementarity problems.

Corollary 4.3. Let E be a 2 uniformly convex and uniformly smooth Banach space, and let X be a nonempty closed convex subset of E. Let $A$ be an operator of X into $E^{*}$ satisfying (C1) and (C2), and let $\left\{S_{i}\right\}_{i \in I}$ and $\left\{T_{i}\right\}_{i \in I}$ be two families of closed quasi- $\phi$-nonexpansive mappings of $X$ into itself with $F:=\bigcap_{i \in I} F\left(T_{i}\right) \cap \bigcap_{i \in I} F\left(S_{i}\right) \cap C P(A, X)$ being nonempty, where $I$ is an index set. Let $\left\{x_{n}\right\}$ be a sequence generated by the following manner:

$$
\begin{gathered}
x_{0} \in X \text { chosen arbitrary, } \\
C_{1, i}=X, \quad C_{1}=\bigcap_{i=1}^{\infty} C_{1, i} \quad x_{1}=\prod_{C_{1}}\left(x_{0}\right) \quad \forall i \in I, \\
w_{n, i}=\prod_{X} J^{-1}\left(J x_{n}-\lambda_{n, i} A x_{n}\right), \\
z_{n, i}=J^{-1}\left(\beta_{n, i}^{(1)} J x_{n}+\beta_{n, i}^{(2)} J T_{i} x_{n}+\beta_{n, i}^{(3)} J S_{i} w_{n, i}\right), \\
y_{n, i}=J^{-1}\left(\alpha_{n, i} J x_{0}+\left(1-\alpha_{n, i}\right) J z_{n, i}\right), \\
C_{n+1, i}=\left\{u \in C_{n, i}: \phi\left(u, y_{n, i}\right) \leqslant \phi\left(u, x_{n}\right)+\alpha_{n, i}\left(\left\|x_{0}\right\|^{2}+2\left\langle u, J x_{n}-J x_{0}\right\rangle\right)\right\}, \\
C_{n+1}=\bigcap_{i \in I} C_{n+1, i}, \\
x_{n+1}=\prod_{C_{n+1}} x_{0}, \quad \forall n \geq 0,
\end{gathered}
$$

where $J$ is the duality mapping on $E$, and $\left\{\lambda_{n, i}\right\},\left\{\alpha_{n, i}\right\}$, and $\left\{\beta_{n, i}^{(j)}\right\}(j=1,2,3)$ are sequences in $(0,1)$ such that

(i) $\lim _{n \rightarrow \infty} \alpha_{n, i}=0$ for all $i \in I$;

(ii) for all $i \in I,\left\{\lambda_{n, i}\right\} \subset[a, b]$ for some $a, b$ with $0<a<b<c^{2} \alpha / 2$, where $1 / c$ is the 2 uniformly convexity constant of $E$;

(iii) $\beta_{n, i}^{(1)}+\beta_{n, i}^{(2)}+\beta_{n, i}^{(3)}=1$ for all $i \in I$ and if one of the following conditions is satisfied:

(a) $\liminf \operatorname{in}_{n \rightarrow \infty} \beta_{n, i}^{(1)} \beta_{n, i}^{(l)}>0$ for all $l=2,3$ and for all $i \in I$,

(b) $\liminf _{n \rightarrow \infty} \beta_{n, i}^{(2)} \beta_{n, i}^{(3)}>0$ and $\lim _{n \rightarrow \infty} \beta_{n, i}^{(1)}=0$ for all $i \in I$.

Then the sequence $\left\{x_{n}\right\}$ converges strongly to $\Pi_{F} x_{0}$, where $\Pi_{F}$ is the generalized projection from $C$ onto $F$.

Proof. From [29, Lemma 7.1.1], we have $\operatorname{VI}(A, X)=C P(A, X)$. From Theorem 3.1, we can obtain the desired conclusion easily. 


\section{Acknowledgments}

The first author would like to thank The Thailand Research Fund, Grant TRG5280011 for financial support. The authors would like to thank the referees for reading this paper carefully, providing valuable suggestions and comments and pointing out a major error in the original version of this paper.

\section{References}

[1] D. Kinderlehrer and G. Stampacchia, An Introduction to Variational Inequalities and Their Applications, vol. 88 of Pure and Applied Mathematics, Academic Press, New York, NY, USA, 1980.

[2] I. Cioranescu, Geometry of Banach Spaces, Duality Mappings and Nonlinear Problems, vol. 62 of Mathematics and Its Applications, Kluwer Academic Publishers, Dordrecht, The Netherlands, 1990.

[3] W. Takahashi, Convex Analysis and Approximation Fixed points, vol. 2 of Mathematical Analysis Series, Yokohama Publishers, Yokohama, Japan, 2000.

[4] M. M. Vainberg, Variational Methods and Method of Monotone Operators, John Wiley \& Sons, New York, NY, USA, 1973.

[5] Ya. I. Alber, "Metric and generalized projection operators in Banach spaces: properties and applications," in Theory and Applications of Nonlinear Operators of Accretive and Monotone Type, A.G. Kartsatos, Ed., vol. 178 of Lecture Notes in Pure and Applied Mathematics, pp. 15-50, Marcel Dekker, New York, NY, USA, 1996.

[6] Ya. I. Alber and S. Reich, "An iterative method for solving a class of nonlinear operator equations in Banach spaces," PanAmerican Mathematical Journal, vol. 4, no. 2, pp. 39-54, 1994.

[7] S. Kamimura and W. Takahashi, "Strong convergence of a proximal-type algorithm in a Banach space," SIAM Journal on Optimization, vol. 13, no. 3, pp. 938-945, 2002.

[8] S. Reich, "A weak convergence theorem for the alternating method with Bregman distances," in Theory and Applications of Nonlinear Operators of Accretive and Monotone Type, A. G. Kartsatos, Ed., vol. 178 of Lecture Notes in Pure and Applied Mathematics, pp. 313-318, Marcel Dekker, New York, NY, USA, 1996.

[9] D. Butnariu, S. Reich, and A. J. Zaslavski, “Asymptotic behavior of relatively nonexpansive operators in Banach spaces," Journal of Applied Analysis, vol. 7, no. 2, pp. 151-174, 2001.

[10] D. Butnariu, S. Reich, and A. J. Zaslavski, "Weak convergence of orbits of nonlinear operators in reflexive Banach spaces," Numerical Functional Analysis and Optimization, vol. 24, no. 5-6, pp. 489-508, 2003.

[11] Y. Censor and S. Reich, "Iterations of paracontractions and firmly nonexpansive operators with applications to feasibility and optimization," Optimization, vol. 37, no. 4, pp. 323-339, 1996.

[12] D. Butnariu and A. N. Iusem, Totally Convex Functions for Fixed Points Computation and Infinite Dimensional Optimization, vol. 40 of Applied Optimization, Kluwer Academic Publishers, Dordrecht, The Netherlands, 2000.

[13] S. Matsushita and W. Takahashi, "A strong convergence theorem for relatively nonexpansive mappings in a Banach space," Journal of Approximation Theory, vol. 134, no. 2, pp. 257-266, 2005.

[14] S. Plubtieng and K. Ungchittrakool, "Strong convergence theorems for a common fixed point of two relatively nonexpansive mappings in a Banach space," Journal of Approximation Theory, vol. 149, no. 2, pp. 103-115, 2007.

[15] X. Qin and Y. Su, "Strong convergence theorems for relatively nonexpansive mappings in a Banach space," Nonlinear Analysis: Theory, Methods \& Applications, vol. 67, no. 6, pp. 1958-1965, 2007.

[16] X. Qin, Y. J. Cho, and S. M. Kang, "Convergence theorems of common elements for equilibrium problems and fixed point problems in Banach spaces," Journal of Computational and Applied Mathematics, vol. 225, no. 1, pp. 20-30, 2009.

[17] H. Iiduka and W. Takahashi, "Weak convergence of a projection algorithm for variational inequalities in a Banach space," Journal of Mathematical Analysis and Applications, vol. 339, no. 1, pp. 668-679, 2008.

[18] F. E. Browder and W. V. Petryshyn, "Construction of fixed points of nonlinear mappings in Hilbert space," Journal of Mathematical Analysis and Applications, vol. 20, no. 2, pp. 197-228, 1967.

[19] H. Iiduka, W. Takahashi, and M. Toyoda, "Approximation of solutions of variational inequalities for monotone mappings," PanAmerican Mathematical Journal, vol. 14, no. 2, pp. 49-61, 2004.

[20] F. Liu and M. Z. Nashed, "Regularization of nonlinear ill-posed variational inequalities and convergence rates," Set-Valued Analysis, vol. 6, no. 4, pp. 313-344, 1998. 
[21] F. E. Browder, "Fixed-point theorems for noncompact mappings in Hilbert space," Proceedings of the National Academy of Sciences of the United States of America, vol. 53, pp. 1272-1276, 1965.

[22] B. Halpern, "Fixed points of nonexpanding maps," Bulletin of the American Mathematical Society, vol. 73, pp. 957-961, 1967.

[23] C. Martinez-Yanes and H.-K. Xu, "Strong convergence of the CQ method for fixed point iteration processes," Nonlinear Analysis: Theory, Methods \& Applications, vol. 64, no. 11, pp. 2400-2411, 2006.

[24] K. Nakajo and W. Takahashi, "Strong convergence theorems for nonexpansive mappings and nonexpansive semigroups," Journal of Mathematical Analysis and Applications, vol. 279, no. 2, pp. 372379, 2003.

[25] X. L. Qin, Y. J. Cho, S. M. Kang, and H. Y. Zhou, "Convergence of a hybrid projection algorithm in Banach spaces," Acta Applicandae Mathematicae, vol. 108, no. 2, pp. 299-313, 2009.

[26] W. Takahashi, Y. Takeuchi, and R. Kubota, "Strong convergence theorems by hybrid methods for families of nonexpansive mappings in Hilbert spaces," Journal of Mathematical Analysis and Applications, vol. 341, no. 1, pp. 276-286, 2008.

[27] S. Reich, "Book Review: Geometry of Banach spaces, duality mappings and nonlinear problems by loana Cioranescu," Bulletin of the American Mathematical Society, vol. 26, no. 2, pp. 367-370, 1992.

[28] I. Cioranescu, Geometry of Banach Spaces, Duality Mappings and Nonlinear Problems, vol. 62 of Mathematics and Its Applications, Kluwer Academic Publishers, Dordrecht, The Netherlands, 1990.

[29] W. Takahashi, Nonlinear Functional Analysis, Fixed Point Theory and Its Application, Yokohama Publishers, Yokohama, Japan, 2000.

[30] K. Ball, E. A. Carlen, and E. H. Lieb, “Sharp uniform convexity and smoothness inequalities for trace norms," Inventiones Mathematicae, vol. 115, no. 3, pp. 463-482, 1994.

[31] Y. Takahashi, K. Hashimoto, and M. Kato, "On sharp uniform convexity, smoothness, and strong type, cotype inequalities," Journal of Nonlinear and Convex Analysis, vol. 3, no. 2, pp. 267-281, 2002.

[32] B. Beauzamy, Introduction to Banach Spaces and Their Geometry, vol. 68 of North-Holland Mathematics Studies, North-Holland, Amsterdam, The Netherlands, 2nd edition, 1985.

[33] R. E. Bruck and S. Reich, "Nonexpansive projections and resolvents of accretive operators in Banach spaces," Houston Journal of Mathematics, vol. 3, no. 4, pp. 459-470, 1977.

[34] Y. J. Cho, H. Y. Zhou, and G. Guo, "Weak and strong convergence theorems for three-step iterations with errors for asymptotically nonexpansive mappings," Computers $\mathcal{E}$ Mathematics with Applications, vol. 47, no. 4-5, pp. 707-717, 2004.

[35] R. T. Rockafellar, "On the maximality of sums of nonlinear monotone operators," Transactions of the American Mathematical Society, vol. 149, pp. 75-88, 1970. 


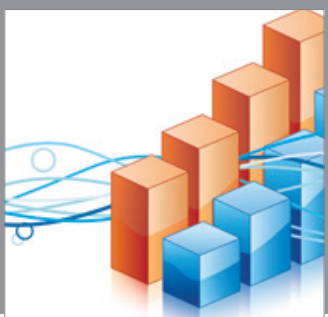

Advances in

Operations Research

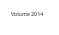

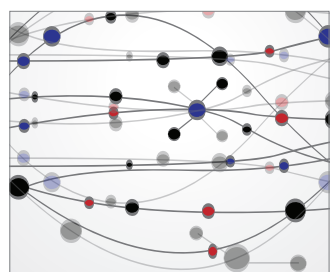

\section{The Scientific} World Journal
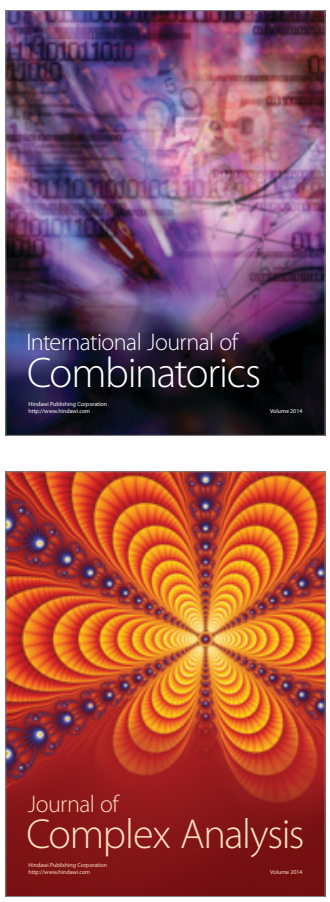

International Journal of

Mathematics and

Mathematical

Sciences
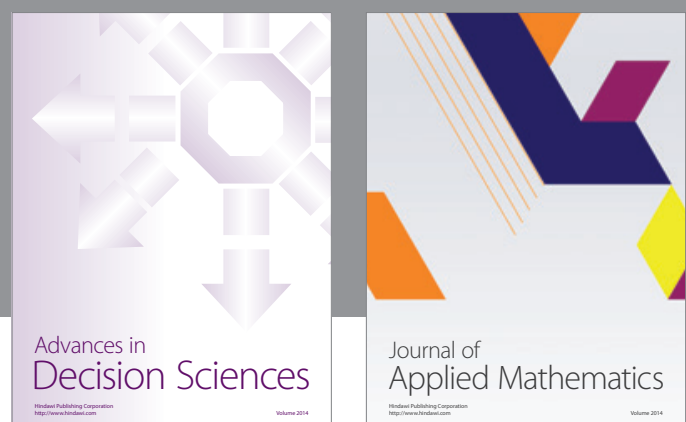

Journal of

Applied Mathematics
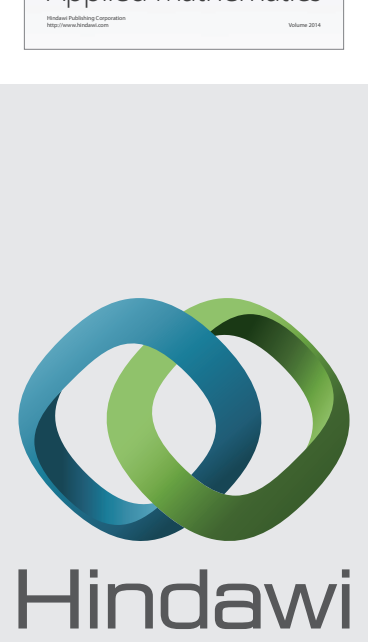

Submit your manuscripts at http://www.hindawi.com
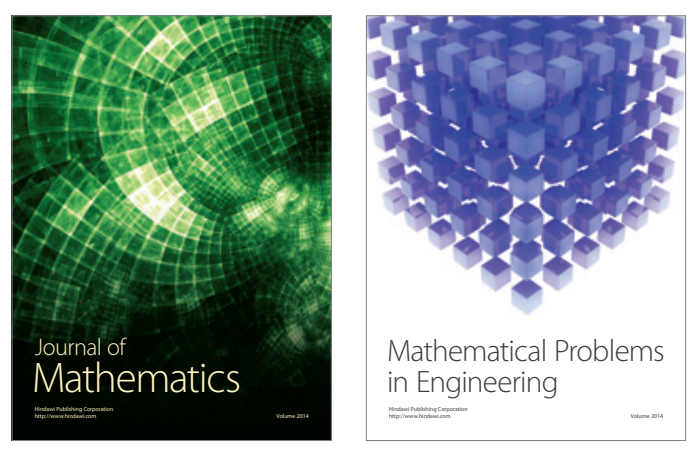

Mathematical Problems in Engineering
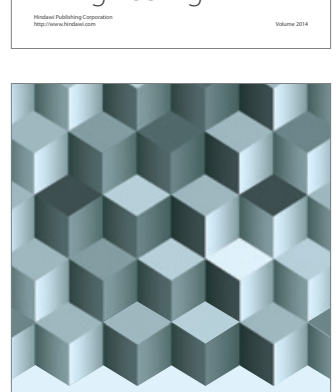

Journal of

Function Spaces
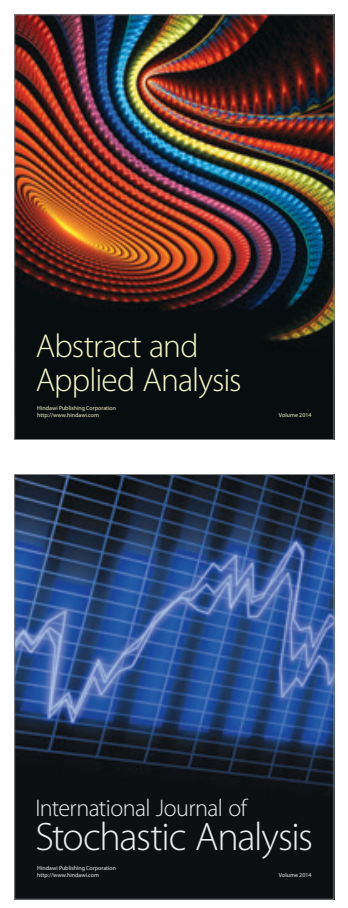

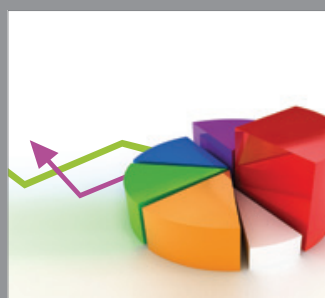

ournal of

Probability and Statistics

Promensencen
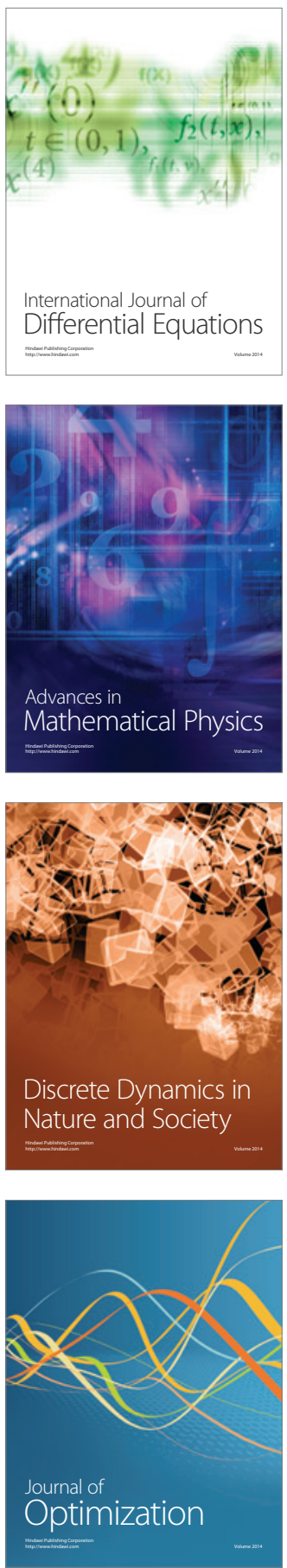